\title{
Temperature trends in the tropical upper troposphere and lower stratosphere: Connections with sea surface temperatures and implications for water vapor and ozone
}

\author{
C. I. Garfinkel, ${ }^{1,2}$ D. W. Waugh, ${ }^{1}$ L. D. Oman, ${ }^{3}$ L. Wang, ${ }^{1}$ and M. M. Hurwitz ${ }^{3,4}$ \\ Received 30 May 2013; revised 8 August 2013; accepted 15 August 2013; published 10 September 2013.
}

[1] Satellite observations and chemistry-climate model experiments are used to understand the zonal structure of tropical lower stratospheric temperature, water vapor, and ozone trends. The warming in the tropical upper troposphere over the past 30 years is strongest near the Indo-Pacific warm pool, while the warming trend in the western and central Pacific is much weaker. In the lower stratosphere, these trends are reversed: the historical cooling trend is strongest over the Indo-Pacific warm pool and is weakest in the western and central Pacific. These zonal variations are stronger than the zonal-mean response in boreal winter. Targeted experiments with a chemistry-climate model are used to demonstrate that sea surface temperature (hereafter SST) trends are driving the zonal asymmetry in upper tropospheric and lower stratospheric tropical temperature trends. Warming SSTs in the Indian Ocean and in the warm pool region have led to enhanced moist heating in the upper troposphere, and in turn to a Gill-like response that extends into the lower stratosphere. The anomalous circulation has led to zonal structure in the ozone and water vapor trends near the tropopause, and subsequently to less water vapor entering the stratosphere. The radiative impact of these changes in trace gases is smaller than the direct impact of the moist heating. Projected future SSTs appear to drive a temperature and water vapor response whose zonal structure is similar to the historical response. In the lower stratosphere, the changes in water vapor and temperature due to projected future SSTs are of similar strength to, though slightly weaker than, that due directly to projected future $\mathrm{CO}_{2}$, ozone, and methane.

Citation: Garfinkel, C. I., D. W. Waugh, L. D. Oman, L. Wang, and M. M. Hurwitz (2013), Temperature trends in the tropical upper troposphere and lower stratosphere: Connections with sea surface temperatures and implications for water vapor and ozone, J. Geophys. Res. Atmos., 118, 9658-9672, doi:10.1002/jgrd.50772.

\section{Introduction}

[2] Despite extensive study, a comprehensive understanding of trends in the tropical tropopause region remains elusive. While many aspects of the climatology of the tropopause are reasonably well understood [Fueglistaler et al., 2009; Ryu and Lee, 2010; Randel and Jensen, 2013], there is still uncertainty as to how it has been changing and by how those changes affect ozone and stratospheric water vapor.

[3] In the time mean in boreal wintertime, zonal and vertical variations in tropical temperature are driven by

\footnotetext{
${ }^{1}$ Department of Earth and Planetary Science, Johns Hopkins University, Baltimore Maryland, USA.

${ }^{2}$ Institute of Earth Sciences, Hebrew University, Jerusalem, Israel.

${ }^{3}$ NASA Goddard Space Flight Center, Greenbelt, Maryland, USA.

${ }^{4}$ Goddard Earth Sciences Technology and Research (GESTAR), Morgan State University, Baltimore, Maryland, USA.

Corresponding author: C. I. Garfinkel, The Institute of Earth Sciences, Hebrew University, Givat Ram Jerusalem, 91904 Israel. (chaim.garfinkel@mail.huji.ac.il)

(C) 2013. American Geophysical Union. All Rights Reserved.

2169-897X/13/10.1002/jgrd.50772
}

convection. Enhanced convection and diabatic heating relative to the zonal mean in the troposphere over the Indo-Pacific warm pool region (hereafter warm pool) lead to colder temperatures relative to the zonal mean near the tropopause [Highwood and Hoskins, 1998; Fueglistaler et al., 2009]. The zonal asymmetry in temperature is also manifested in key trace gases, for example, in water vapor and ozone (e.g., Fueglistaler et al., [2009, Figure 5]). The cold temperatures over the warm pool region in boreal winter govern the amount of water vapor that can reach higher in the stratosphere [Mote et al., 1996; Fueglistaler et al., 2004].

[4] Temperatures in the lower stratosphere and upper troposphere (hereafter LS and UT) have been changing. While many have focused on the zonal-mean component of the temperature trends [e.g., Randel et al., 2009; Fu et al., 2010; Seidel et al., 2011; Young et al., 2011; Wang and Waugh, 2012], our attention here is on the zonally asymmetric component (i.e., the zonal structure) of the trend, and in particular, on the trends near the coldest point in the tropopause region (hereafter, cold point). While most studies seem to find a cooling of the cold-point region (e.g., Zhou et al. 
[2001]; see Wang et al. [2012] for a recent discussion), some suggest the opposite. For example, Scaife et al. [2003] find that El Niño causes increased stratospheric water vapor, and then argue that El Niño frequency has increased, leading to increased stratospheric water vapor. In addition, Shu et al. [2011, cf. Figure 11] find that the cold-point temperature increases if sea surface temperatures (hereafter SSTs) are increased everywhere in a model.

[5] This paper focuses on documenting, and understanding the cause of, the zonal structure of the temperature trends in the UT and LS in boreal winter. Specifically, we are interested in isolating the trends that are associated with changes in observed SSTs and their subsequent impact on upper tropospheric diabatic heating. We then focus on the impacts of the trends in diabatic heating on the circulation in the UT and LS, and subsequently on ozone and water vapor.

[6] Rosenlof and Reid [2008] find a correlation between cold-point temperatures and SSTs in the warm pool region in available radiosonde data. Deckert and Dameris [2008] find a relationship between warm pool SSTs and zonally averaged tropical upwelling in boreal summer in model experiments. On interannual timescales, Kiladis et al. [2001], Calvo Fernández et al. [2004], Garcia et al. [2007], Scaife et al. [2003], and Scherllin-Pirscher et al. [2012] (among others) connect cold-point temperatures and SST anomalies in response to El Niño-Southern Oscillation (ENSO). This study builds on this previous work by focusing on how warming SSTs in the warm pool region and in the Indian Ocean sector over the satellite era are influencing the zonal structure of the temperature trend in the UT and near the cold point in satellite data and in models. Specifically, we (1) document the zonal structure of the lower stratospheric temperature trends in satellite data, (2) show that models can reproduce it, and then understand its causes in the model, and (3) show that this zonal structure is important in determining stratospheric ozone and water vapor trends.

[7] This paper is organized as follows. After explaining the data in section 2, we document the observed and modeled temperature trends, and discuss their connection to SST trends, in section 3. We then discuss the implications of these trends for lower stratospheric water vapor and ozone in section 4. We present the impact of projected future changes in SSTs in section 5, and then discuss previous work in section 6 .

\section{Data and Methods}

\subsection{Data}

[8] We evaluate the connection between SSTs and upper tropospheric and lower stratospheric tropical temperatures in both the satellite record and integrations of a range of Chemistry-Climate Models (CCMs). The four data sources used in this study are summarized in Table 1.

[9] Microwave Sounding Units (MSU) data sets produced by the Remote Sensing Systems (RSS) are used to constrain the observed historical temperature trends (available at http://www.ssmi.com/msu/msu_data description.html;"A" in Table 1). Specifically, we use the "temperature total troposphere" (TTT) product for free tropospheric temperatures and the "temperature lower stratosphere" (TLS) product for the lower stratosphere [Mears et al., 2003; Mears and Wentz, 2009].
[10] The first group of model integrations evaluated ("B" in Table 1) is the "REFB1" simulations as defined by the Chemistry-Climate Model Validation project phase 2 (CCMVal-2) [SPARC-CCMVal, 2010; Eyring et al., 2008] and provided to the CCMVal-2 database. In these simulations, the boundary and forcing conditions from 1960 until 2004 were used to force each model. Specifically, the simulations are driven by time varying emissions of ozone precursors, concentrations of ozone depleting substances and greenhouse gases (hereafter ODS and GHG), SSTs, volcanic emissions, solar output, and sea ice. We consider 32 integrations, from 18 models, for which data are available.

[11] The second and third groups of model integrations ("C" and "D" in Table 1) are of the Goddard Earth Observing System Chemistry-Climate Model, version 2 (GEOSCCM) [Rienecker et al., 2008 and Hurwitz et al., 2010, section 2.2]. The GEOSCCM couples the GEOS-5 atmospheric General Circulation Model (GCM) [Rienecker et al., 2008] with a comprehensive stratospheric chemistry module [Pawson et al., 2008]. The model has 72 vertical layers, with a model top at $0.01 \mathrm{hPa}$, and all simulations discussed here were performed at $2^{\circ}$ latitude $\times 2.5^{\circ}$ longitude horizontal resolution. The convection scheme used in GEOSCCM is based on Relaxed Arakawa-Schubert [Moorthi and Suarez, 1992; Rienecker et al., 2008; Molod et al., 2012]. The representation of stratospheric water vapor and lower stratospheric temperatures by an earlier version of GEOSCCM is graded highly by SPARC-CCMVal [2010] and Gettelman et al. [2010] as compared to observations and to the multimodel mean of an ensemble of CCMs.

[12] The model vertical levels between 150 and $50 \mathrm{hPa}$ are located at 139.1, 118.3, 100.5, 85.4, 72.6, 61.5, and 52.0 $\mathrm{hPa}$. Data were archived at the $150,100,85,70$, and $50 \mathrm{hPa}$ levels for all variables except for the vertical velocity, for which the $85 \mathrm{hPa}$ level is unavailable. The tropopause height is defined using a blended approach which takes the lower of a potential vorticity based tropopause and a thermally based tropopause. In the tropics, the thermal definition dominates, and it is based on identifying the left-most kink in a Skew-T $\log$ P diagram.

[13] Data source $\mathrm{C}$ is a six-member ensemble of GEOSCCM in which the SSTs from January 1980 to December 2006 force each 27 year integration [Rayner et al., 2003]. Otherwise, there is no externally forced variability. GHG and ODS concentrations represent the year 2005 in all ensemble members. Variability related to the solar cycle and volcanic aerosols is not considered. Each of the six differs slightly in their physical parameterizations, whereby two of the ensemble members include an internally generated Quasi-Biennial Oscillation and four do not. All trends shown here are robust to excluding those ensemble members with a Quasi-Biennial Oscillation. By combining the six together, we form a more robust assessment of the changes forced by SSTs in GEOSCCM. Therefore, in our figures, we emphasize regions where the ensemble members agree. The key point is that these simulations isolate the impact of SST variations from 1980 to 2006 on the UTLS.

[14] Data source D is a series of four GEOSCCM experiments which isolate the effects of future gas composition changes and SST changes. Each of these experiments isolates one aspect of the current or future climate, and each one extends for 50 years. In the first, the model is forced with 
Table 1. Data Sources

\begin{tabular}{llcr}
\hline & Source & Description & References \\
\hline A & MSU RSS & Lower stratosphere and troposphere & Mears et al. [2003] and Mears and Wentz [2009] \\
B & CCMVal-2 & 32 integration and 18 models & SPARC-CCMVal [2010] and Eyring et al. [2008] \\
C & GEOSCCM & Six members and SST only & Rienecker et al. [2008], Hurwitz et al. [2010], and Molod et al. [2012] \\
D & GEOSCCM & pSSTpCL, pSSTfCL, fSSTpCL, and fSSTfCL, & Hurwitz et al. [2011] \\
\hline
\end{tabular}

present-day ENSO neutral SSTs and present-day concentrations of $\mathrm{CO}_{2}$, ODS, and methane (hereafter pSSTpCL); Hurwitz et al. [2011] discuss the setup of this simulation in detail. In the second, the same present-day SSTs are used, but the radiatively active gas concentrations represent the climate at the end of the century (hereafter pSSTfCL). In the third, future ENSO neutral SSTs are used, but the radiatively active gas concentrations represent the present climate (hereafter fSSTpCL). In the fourth, both SSTs and radiatively active gas concentrations represent the future (hereafter fSSTfCL). For the experiments with future gas concentrations, concentrations of GHGs [Solomon et al., 2007, A1B scenario] and ODSs [World Meteorological Organization, 2011, A1 scenario] are both fixed at 2100 values. For the experiments with future SSTs, SSTs and sea ice are taken from the Community Climate System Model, version 3.0 (CCSM3) A1B scenario simulations of the 21st century submitted to the Coupled Model Intercomparison Project, Phase 3 (CMIP3) (http://cmip-pcmdi. llnl.gov/cmip3_overview.html). These experiments remove the influence of ENSO on future trends in tropical temperatures, since ENSO neutral SSTs are prescribed in all cases. M. M. Hurwitz et al. (Sensitivity of the atmospheric response to warm pool El Niño events to modeled SSTs and future climate forcings, submitted to Journal of Geophysical Research, 2013) use these simulations to separate the impacts of SSTs and climate conditions on extratropical ENSO teleconnections. Similar experiments were performed by Kodama et al. [2007], Olsen et al. [2007], and Garny et al. [2011], but they did not discuss the zonal structure of the tropical trends. The key point is that these model integrations can isolate impacts of modeled SST fields and future climate conditions on the zonal structure of temperature and water vapor trends in the tropical Pacific.

\subsection{Methods}

[15] The trends are calculated with a linear least squares fit from January 1980 to December 2004, as this is the common period among the three data sources discussed in this paper. We have examined the trends in MSU/AMSU data from 1979 to the present and the trends in the GEOSCCM SSTonly integrations until the end of 2006, and they are similar to those shown here. We calculate temperature trends in the model at individual pressure levels. We elect not to weight model anomalies by the MSU vertical weighting functions, as temperature structures in the LS forced by equatorial tropospheric waves have fine-vertical spatial structure (Grise and Thompson [2013] and Figure 4 below). Rather, we consider the MSU temperature trends as representing a blurred version of the fine-structured trends.

[16] For the six-member GEOSCCM-targeted ensemble and the CCMVal-2 data, statistical robustness is determined by evaluating the fraction of the ensemble members who agree on the sign of the trend. Color is added when 5 or 6 out of 6 for the GEOSCCM-targeted integrations and 27 or 30 out of 32 for the CCMVal-2 integrations agree on the sign of the trend (a convention similar to that of Solomon et al. [2007]). The vertical velocity was not archived for one of the six integrations, and so coloring on the figures for vertical velocity indicates that four or all of the ensemble members agree on the sign of the trend. For the GEOSCCM integrations which isolate the future changes in UTLS temperatures, the Student's t difference of means test is used to ascertain significance.

[17] In diagnosing the response to changing SSTs in GEOSCCM, we examine the heating due to moist processes as simulated by the model. The heating includes all processes that involve phase changes in the atmosphere, such as large-scale condensation, convective clouds, and all rain and cloud formation. It does not include any radiative effects or turbulence effects.

\section{Temperature Trends}

\subsection{Observations}

[18] We first document the lower stratospheric temperature trends in observations, and our specific focus here is on the zonal structure of the trend. Figure 1a shows the temperature trends for January, February, and March (JFM) in the Tropics from the MSU data in the LS. The central and eastern Pacific regions cool less than the zonal mean, while the warm pool region cools more than the zonal mean. Figure $1 \mathrm{~b}$ shows the temperature trends for the tropospheric MSU channel. The zonal structure of the tropospheric trend is out of phase with the structure of the lower stratospheric trends in JFM. Namely, lower stratospheric temperatures are relatively cooler where tropospheric temperatures are relatively warmer. These two figures are summarized by Figure 1c, which clearly shows the out-of-phase behavior. Figure 1c also demonstrates that the trend is robust to changing the period over which the trend is calculated.

[19] The zonally asymmetric component of the trend is strongest in JFM. This is demonstrated in Figure 2, which shows the equatorial temperature trends in both MSU channels for each calendar month. The zonally asymmetric component of the trend is of similar magnitude to the zonalmean component of the trend: in the annual average, the zonal-mean cooling of the TLS channel is $-0.37 \mathrm{~K} /$ decade, while the magnitude of the zonal structure (i.e., the difference between the region that cools most strongly and most weakly) is $-0.26 \mathrm{~K} /$ decade. In February and in March, the magnitude of the zonal structure exceeds the zonally symmetric temperature trend. The zonal structure is also evident in Fu et al. [2006], in Seidel et al. [2011, Figure 8], and in 

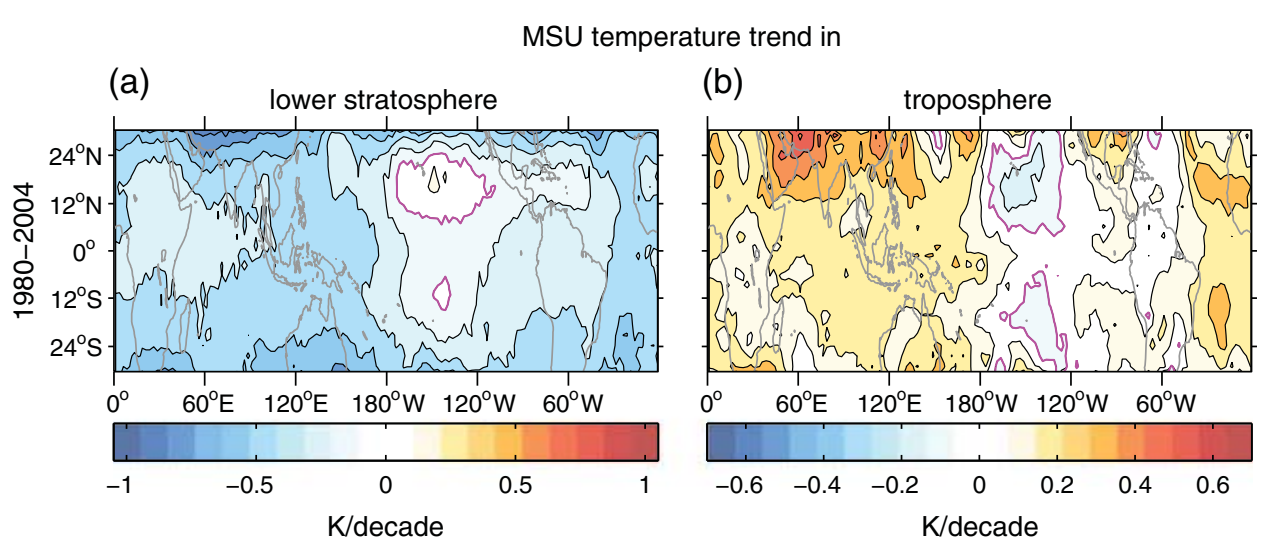

(c)
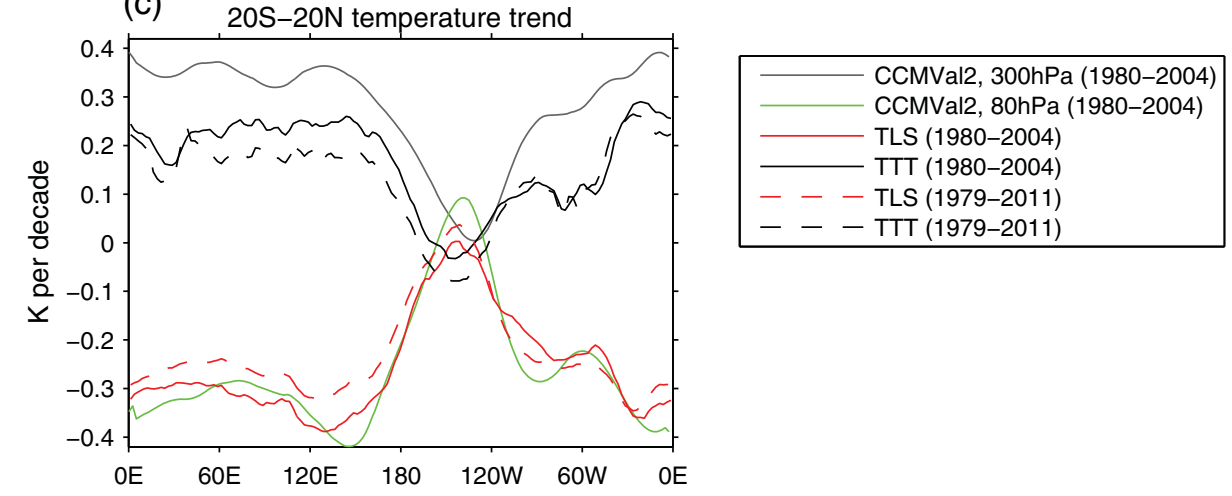

Figure 1. Temperature trend in Tropics for the RSS (a) lower stratosphere (TLS) and (b) troposphere (TTT) channels during JFM. The zero line is magenta, and the contour interval is $0.15 \mathrm{~K} /$ decade for TLS and $0.1 \mathrm{~K} /$ decade for TTT. (c) Summary of the tropical temperature trends in JFM.

radiosonde data [Rosenlof and Reid, 2008]. These temperature trends could have important impacts on water vapor, etc. (to be discussed in section 4), so it is important to understand their source. The rest of this section is devoted to understanding and explaining the origin of the zonal structure of the temperature trends.

\subsection{CCMVal-2 Models}

[20] We start with the temperature trends at 250 and 100 $\mathrm{hPa}$ in the multimodel CCMVal-2 database. Figures $3 \mathrm{a}$ and $3 \mathrm{~b}$ show the temperature trends for the CCMVal-2 multi- model mean. It is clear that there is a strong correspondence between the modeled and observed trends in Figures 3a, 3b, and 2: the models can successfully reproduce these trends. (There are some quantitative differences between the models and satellite data, and these could be due to many causes, including the broad weighting function of the MSU, which smears out some of the structure at the fine-vertical scales, or the availability of multiple ensemble members for the model response.) The agreement between the multimodel mean of the CCMVal-2 response and the MSU trend is evident in the LS in Figure 1c as well; in the UT, the models accurately

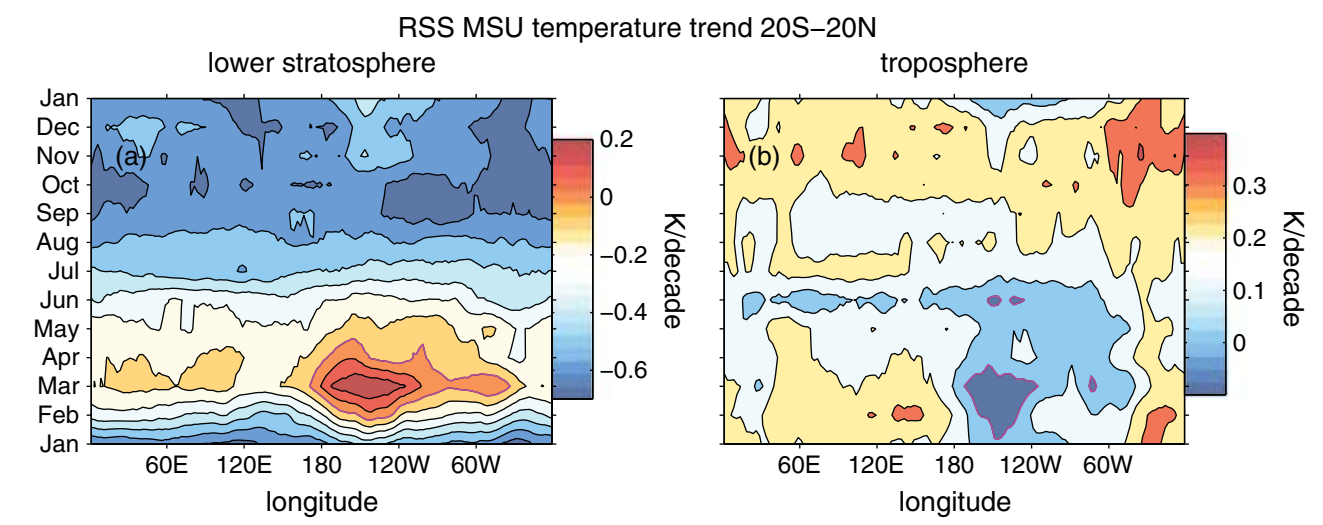

Figure 2. Seasonal evolution of the tropical temperature trends for RSS lower stratosphere and tropospheric channels. The zero line is magenta, and the contour interval is $0.1 \mathrm{~K} /$ decade. 


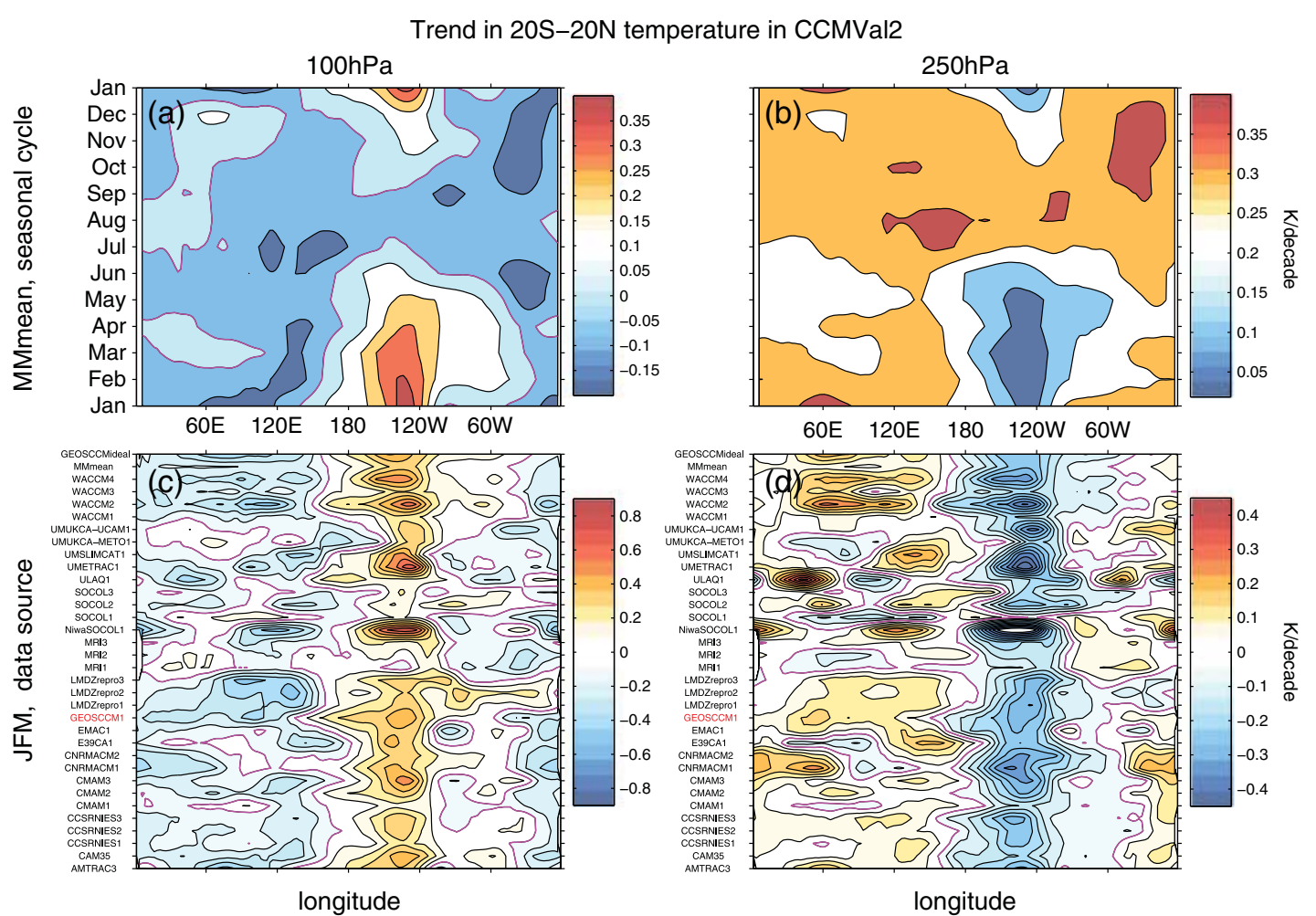

Figure 3. Summary of temperature trends at (a) 100 and (b) $250 \mathrm{hPa}$ in the Tropics in the multimodel mean for each calendar month; and ( $c$ and d) the deviation from the zonal mean in the Tropics in JFM in each model, in the multimodel mean and in the GEOSCCM-targeted integrations. The GEOSCCM run contributed to CCMVAL-2 is below the midpoint of the ordinate and is labeled in red for clarity. The zero line is magenta, and the contour interval is $0.1 \mathrm{~K} /$ decade for Figures $3 \mathrm{a}-3 \mathrm{c}$ and $0.05 \mathrm{~K} /$ decade for Figure $3 \mathrm{~d}$.

capture the zonal variations of the trend even though they overestimate the zonal-mean warming (a bias also present in CMIP3 and CMIP phase 5) [e.g., Seidel et al., 2012; Po-Chedley and Fu, 2012].

[21] Figures $3 \mathrm{c}$ and $3 \mathrm{~d}$ show the zonal structure of the temperature trends in JFM for each model individually and also for the multimodel mean. In the UT, nearly all models suggest a cooling from $150 \mathrm{~W}$ to $120 \mathrm{~W}$ and a warming over the Indian and Warm Pool region. The anomalies near the tropopause are opposite to those in the UT. In fact, the CCMVal-2 models agree more closely on the zonal structure of the temperature trend as compared with the magnitude of the zonal-mean temperature trend. Note that the GEOSCCM CCMVal-2 integration appears to capture this behavior, and the magnitude of the trend as simulated by GEOSCCM falls within the range that is simulated by the other models (Figures $3 \mathrm{c}$ and $3 \mathrm{~d}$ ).

[22] The vertical structure of the changes in the multimodel mean of the CCMVal-2 models is shown in Figures $4 \mathrm{a}$ and $4 \mathrm{~b}$. In the UT, the warming is present mainly in the Indian Ocean and Warm Pool region, while the West-Central Pacific does not warm (Figure 4a). Near the lowermost stratosphere $(\sim 85 \mathrm{hPa})$, on the other hand, cooling is present in the Indian Ocean and Warm Pool region while the central Pacific warms. In other words, the sign of the regional temperature anomaly reverses between 100 and $250 \mathrm{hPa}$. This quadrupole effect is more clearly seen in Figure $4 \mathrm{~b}$, which highlights the zonal structure of the trend.

\subsection{SST-Only GEOSCCM Ensemble}

[23] In this section, GEOSCCM simulations in which the only source of variability is SST (data source " $C$ " in Table 1) are used to understand the cause of the zonal structure of the trends in JFM. Specifically, we demonstrate that local changes in SST are contributing to the observed zonal structure of the temperature trends. The vertical versus longitudinal structure of the temperature trends is shown in Figures $4 \mathrm{c}$ and $4 \mathrm{~d}$. They exhibit a quadrupole pattern between 250 and $100 \mathrm{hPa}$ and in the western and central Pacific in JFM. The zonal structure is similar to that in the CCMVal-2 models (Figures $4 \mathrm{~b}$ and $4 \mathrm{~d}$ ). Note that the response in the CCMVal models should not be expected to be identical to that in the GEOSCCM-targeted integrations, as the CCMVal integrations include not only changing SSTs but also changing $\mathrm{CO}_{2}$ and ODS concentrations which act to cool the stratosphere. However, the quantitative similarity between the zonal structure strongly suggests that SST changes have driven the changes in upper tropospheric and lower stratospheric temperatures in the more comprehensive model integrations and satellite data. The zonal structure of the response in the GEOSCCM-targeted integrations is stronger than in the multimodel CCMVal-2 mean (Figures 3a and $3 \mathrm{~b}$ ), but it falls within the inter-model range. Finally, the vertical structure of the trends in NASA's ModernEra Retrospective Analysis for Research and Applications (MERRA) [Rienecker et al., 2011] reanalysis is shown in Figures $4 \mathrm{e}$ and $4 \mathrm{f}$; the zonal structure of the temperature 
Temperature trend 20S-20N, JFM (K/decade)
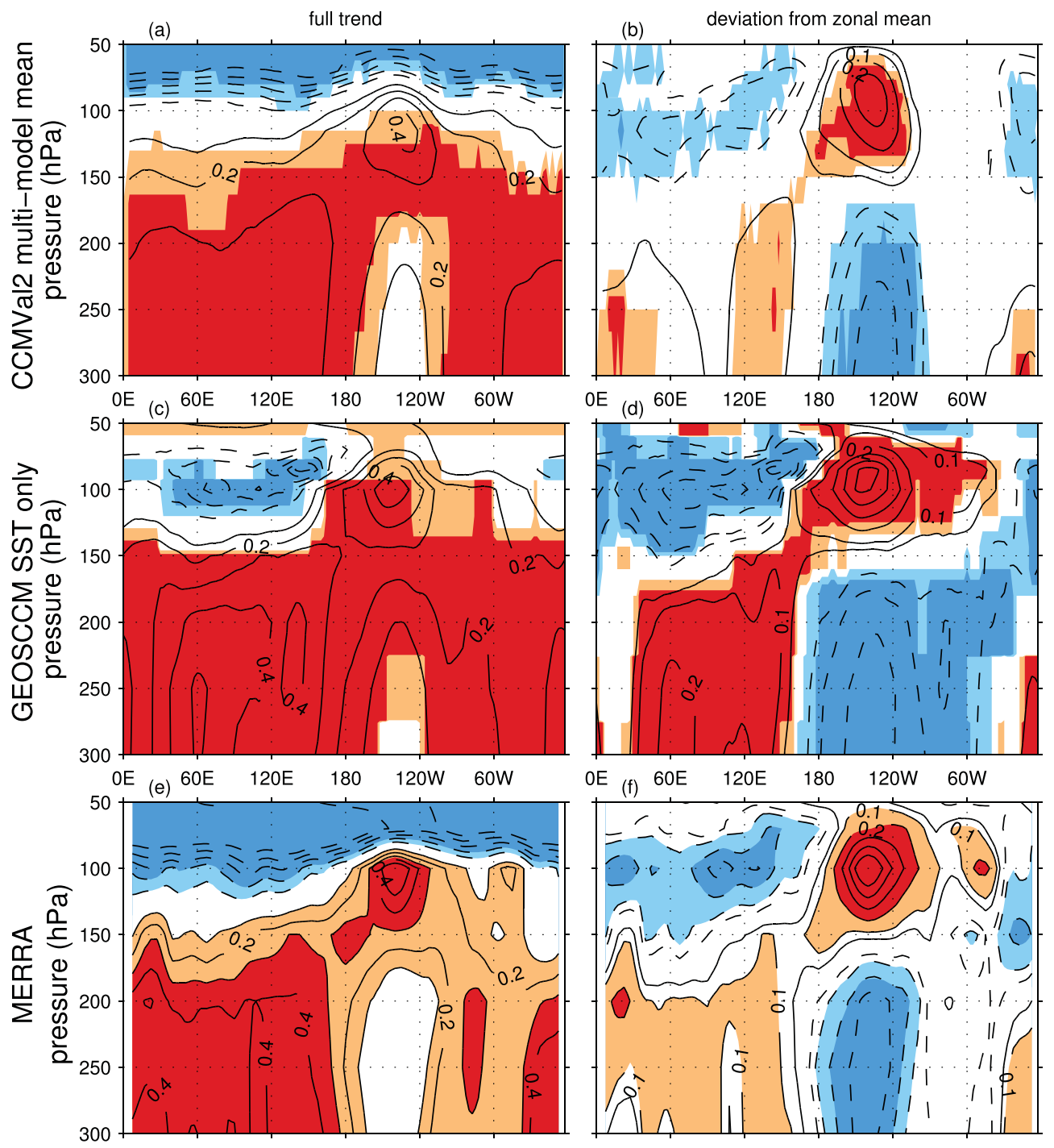

Figure 4. Vertical structure of the trend in JFM in the Tropics in the multimodel mean of the CCMVal-2 models. (a) Full trend, (b) deviation from the zonal mean. (c and d) like Figures $4 \mathrm{a}$ and $4 \mathrm{~b}$ but for the GEOSCCM SST-only experiments. The contour interval is $0.1 \mathrm{~K} /$ decade, and the $\pm 0.05 \mathrm{~K} / \mathrm{decade}$ contour is added for Figures $4 \mathrm{~b}$ and $4 \mathrm{~d}$. The zero contour is omitted. Statistical robustness of the trend is indicated by red and blue as discussed in section 2.2. (e and f) Like Figures $4 \mathrm{a}$ and $4 \mathrm{~b}$ but for the MERRA reanalysis, and color denotes large trends.

trends in all three data sources agrees, which implies that reanalysis data can capture this effect too.

[24] We now seek to explain the forcing of these temperature trends, and in particular their relationship to changing SSTs. Figure 5a shows the trend in SST over this time period. The increases in SST over the Indian ocean and over the far-western Pacific are collocated with warming in the upper troposphere, while the cooling and near-neutral SST trends in the Pacific ocean are beneath cooling in the upper troposphere. This is shown explicitly in Figures 6a and $6 \mathrm{~b}$, which compares the zonal structure at each longitude grid point of the temperature trends at 250 and $100 \mathrm{hPa}$ to that of the SST trends: the correlation coefficient is 0.83 and -0.76 respectively. The correlation coefficient between tropopause temperature trends and the SST trends at each longitude grid point in the Tropics is large in nearly every model integrations included in this study (Figure 7). The correlation coefficient in the MSU data between SST trends and TTT and TLS is 0.87 and -0.89 . While the dynamical response to changing SSTs is also important in determining the structure of the tropopause temperature trends (and this dynamical response is likely different among different models), these highly significant correlations strongly suggest that the structure of the atmospheric temperature trends is dominated by the structure of the SST trend.

[25] The increase Indian Ocean sector SST anomalies near $60^{\circ} \mathrm{E}$ are directly associated with global warming [Knutson et al., 1999; Hoerling et al., 2004; Knutson et al., 2006], and thus the temperature responses in this region can be attributed to global warming. In contrast, SST trends in 

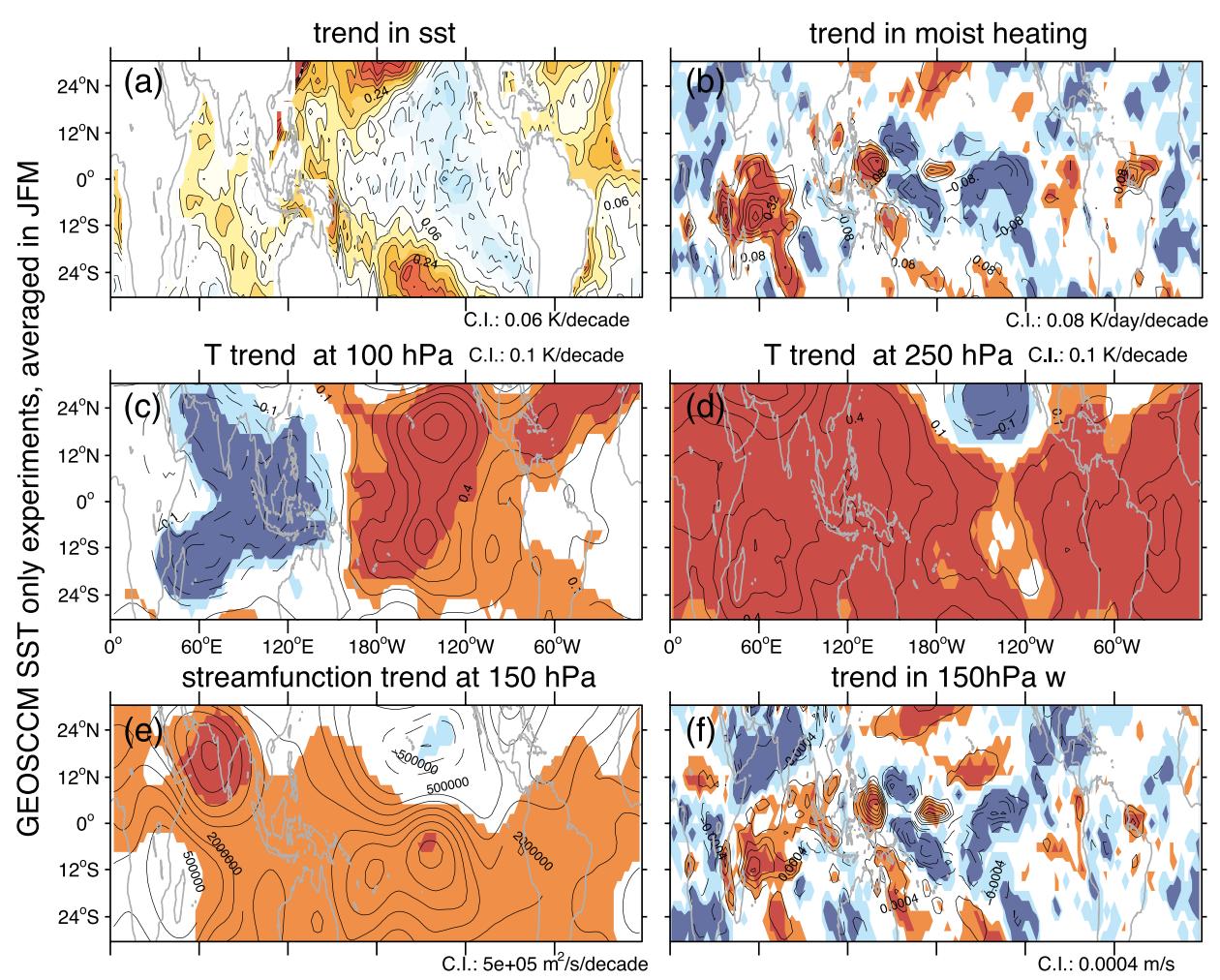

Figure 5. Trend in JFM in the ensemble mean of the SST-only GEOSCCM ensemble. (a) Sea surface temperatures, the contour interval is $0.06 \mathrm{~K} /$ decade; (b) moist heating pressure weighted from 500 to $150 \mathrm{hPa}$, the contour interval is $0.08 \mathrm{~K} /$ day/decade except that the $0.02 \mathrm{~K} /$ day/decade contour is added; (c) lower stratospheric and (d) upper tropospheric temperature, the contour interval is $0.1 \mathrm{~K} / \mathrm{decade}$; (e) stream function at $150 \mathrm{hPa}$, the contour interval is $5 \mathrm{e} 5 \mathrm{~m}^{2} / \mathrm{s} / \mathrm{decade}$; and (f) vertical velocity at $150 \mathrm{hPa}$, the contour interval is $4 \mathrm{e}-3 \mathrm{~m} / \mathrm{s} /$ decade. The zero contour is omitted. Statistical robustness of the trend is indicated by red and blue as discussed in section 2.2.

the Pacific Ocean are more uncertain and are subject to aliasing from ENSO (this potential aliasing will be discussed in section 6) [e.g., Scaife et al., 2003; Sohn et al., 2012]. In summary, SST anomalies have driven anomalies in the upper tropospheric and lower stratospheric temperature.

[26] We now present a possible mechanism on how the anomalous SSTs have driven the lower stratospheric response. Anomalous SSTs force anomalous convection, and Gill [1980] provides a theory for how upper level diabatic heating can lead to a pattern of divergence. Highwood and Hoskins [1998, section 5] have shown that the resulting circulation strongly impacts tropopause temperatures. We therefore analyze the moist heating trends before returning to the temperature and circulation trends. Figure $5 \mathrm{~b}$ shows the upper tropospheric (pressure weighted from 500 to $150 \mathrm{hPa}$ ) heating due to moist processes (as defined in section 2.2) in the six member GEOSCCM ensemble. There is a clear enhancement in upper level heating in the western Indian Ocean near $60^{\circ} \mathrm{E}$ and in the warm pool region near $140^{\circ} \mathrm{E}$. Figures $8 \mathrm{a}$ and $8 \mathrm{e}$ show the trend in tropical moist heating with longitude and altitude. These features are present up to the tropopause (Figures $8 \mathrm{a}$ and $8 \mathrm{e}$ ), though they weaken substantially above $200 \mathrm{hPa}$. The warm anomalies in the Indian ocean region and in the warm pool region in Figures $4 \mathrm{c}$ and $4 \mathrm{~d}$ peak near the longitude of the peak upper level heating. In contrast, there is reduced upper level heating near $120^{\circ} \mathrm{W}$, and this appears to be associated with local cold anomalies at $250 \mathrm{hPa}$ in this region in Figures $4 \mathrm{c}$ and $4 \mathrm{~d}$. Thus, heating due to moist processes appears to be driving the temperature response.

[27] We now consider the circulation response driven by the trend in upper level heating. The meridional and zonal variations in the temperature trends at 100 and $250 \mathrm{hPa}$ are highlighted in Figures $5 \mathrm{c}$ and $5 \mathrm{~d}$. As mentioned above, the Warm Pool and Indian Ocean region cool while the central and eastern Pacific warm at $100 \mathrm{hPa}$, and vice versa at $250 \mathrm{hPa}$. The temperature anomalies near the warm pool resemble a " $>$ " sign or a horseshoe pattern, which strongly resemble those shown in the model of Highwood and Hoskins [1998, section 5] and in reanalysis data on seasonal timescales by Nishimoto and Shiotani [2012], in response to such heating. In contrast, the temperature anomalies over the Central Pacific resemble a meridional dipole straddling the equator, consistent with the trends in moist heating. The upper level stream function also bears close resemblance to that of Gill [1980] and Highwood and Hoskins [1998] (cf. Figure 5e; stream function changes at 100 and $300 \mathrm{hPa}$ are similar): a Kelvin wave is present near $150^{\circ} \mathrm{W}$ (collocated with the temperature dipole), and an equatorially trapped Rossby wave is present over the western Indian Ocean. The extrema associated with the Rossby wave are stronger than those of the Kelvin wave, and the extrema in the winter (northern) hemisphere are slightly stronger than the extrema in the summer hemisphere. The net effect is that the total 

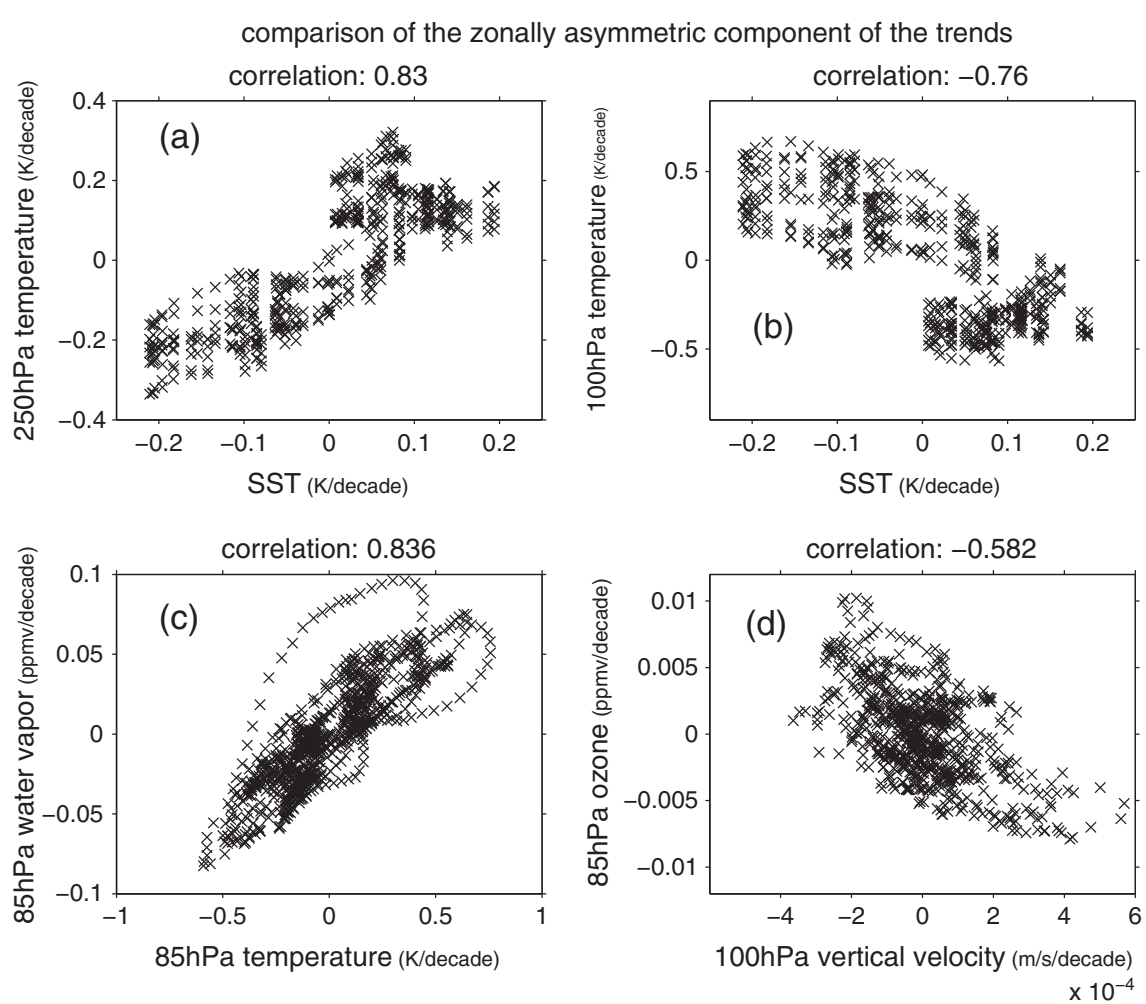

Figure 6. (a-b) Relationship between the zonal asymmetries of the SST trends and the temperature trends at 250 and $100 \mathrm{hPa}$ for each longitudinal grid point averaged from $20^{\circ} \mathrm{S}-20^{\circ} \mathrm{N}$ in the GEOSCCM SST-only ensemble in JFM, (c) like Figure 6a but for $85 \mathrm{hPa}$ temperature and water vapor, and (d) like Figure 6a but for $100 \mathrm{hPa}$ vertical velocity and $85 \mathrm{hPa}$ ozone.

trend in the stream function field resembles a quadrupole. All of these features generally resemble those shown in Highwood and Hoskins [1998, Figures 8 and 11], though some of the details differ as the heating trend is not idealized as in Highwood and Hoskins [1998]. Anomalies in geopotential height resemble those in Ting and Held [1990] who investigated the response to a dipole SST anomaly in an idealized model (not shown). In addition, the moist heating anomalies force equatorial vertical velocity anomalies, which are shown in Figure 5f. Vertical velocity at $150 \mathrm{hPa}$ closely follows the pattern of upper tropospheric diabatic heating, such that there is enhanced upwelling over the Indian Ocean and near and just east of the maritime continent. The vertical velocity anomalies extend to the tropopause (Figures $8 \mathrm{~b}$ and $8 \mathrm{f}$ ), above the region where moist heating is near zero (Figures $8 \mathrm{a}$ and $8 \mathrm{e}$ ). The continuation of the vertical velocity trend above the altitude in which moist heating trends are strong is consistent with

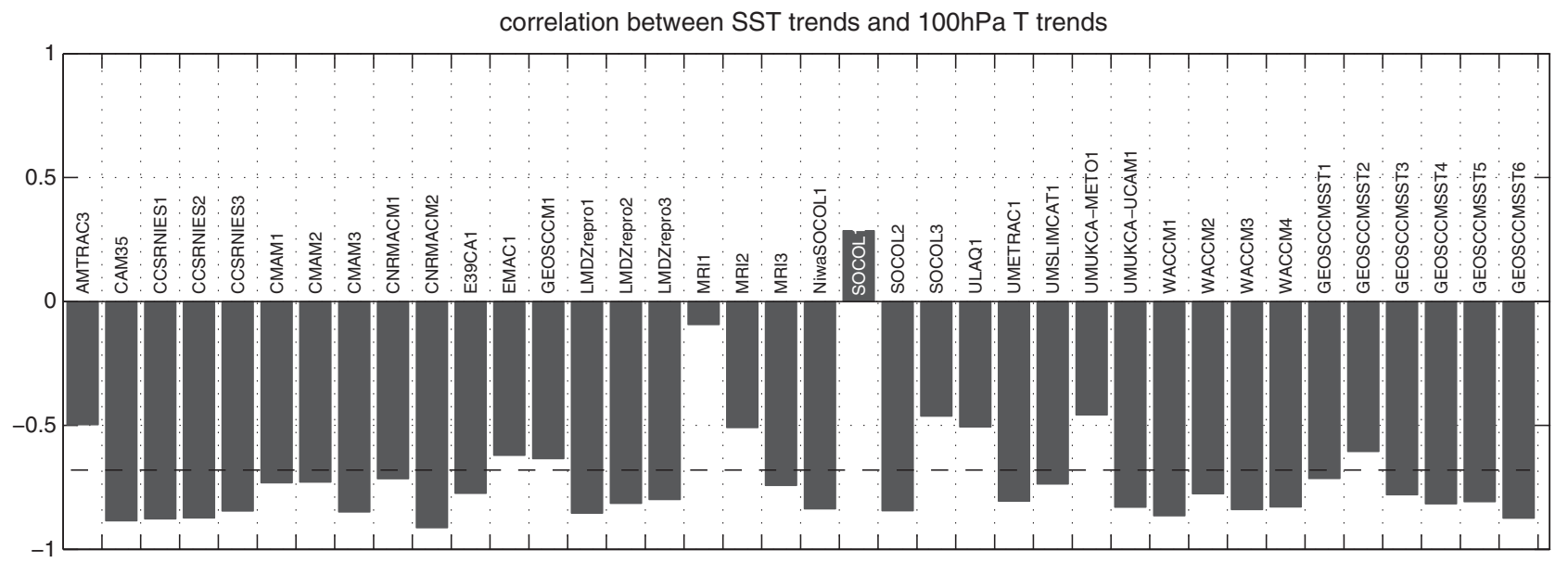

Figure 7. Summary of longitude-by-longitude correlation coefficient between tropical temperatures at $100 \mathrm{hPa}$ and SSTs in each model. The dashed line indicates the mean correlation coefficient among the CCMVal-2 models. 
vertical structure of JFM tropical (20S-20N) trend from 1980-2004 in the GEOSCCM SST only 6 member ensemble
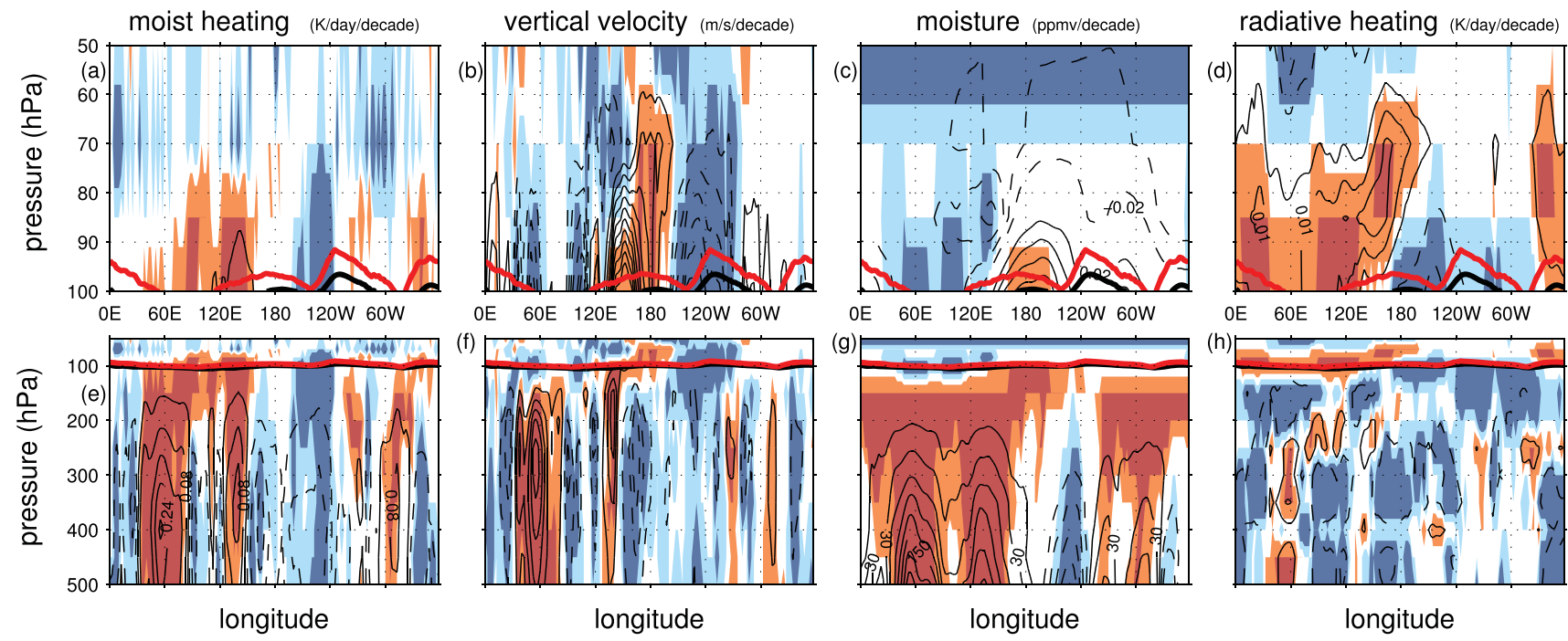

Figure 8. Vertical structure of the trend in JFM in the ensemble mean of the SST-only six-member ensemble. (a and e) Moist heating, ( $b$ and $f$ ) vertical velocity, (c and g) moisture, and ( $\mathrm{d}$ and $\mathrm{h}$ ) radiative heating. The contour interval for Figures $8 \mathrm{a}$ and $8 \mathrm{~d}$ is $0.005 \mathrm{~K} /$ day/decade, Figure $8 \mathrm{~b}$ is $3 \mathrm{e}-5 \mathrm{~m} / \mathrm{s} / \mathrm{decade}$, Figure $8 \mathrm{c}$ is $0.02 \mathrm{ppmv} /$ decade, Figures $8 \mathrm{e}$ and $8 \mathrm{~h}$ is $0.04 \mathrm{~K} /$ day/decade (except that the $0.01 \mathrm{~K} /$ day/decade contour is added for Figure $8 \mathrm{~h}$ ), Figure $8 \mathrm{f}$ is $3 \mathrm{e}-4 \mathrm{~m} / \mathrm{s} / \mathrm{decade}$, and Figure $8 \mathrm{~g}$ is $20 \mathrm{ppmv} / \mathrm{decade}$. The zero contour is omitted. Figures $8 \mathrm{a}-8 \mathrm{~d}$ emphasize the lower stratospheric trends, while Figures $8 \mathrm{e}-8 \mathrm{~h}$ emphasize the tropospheric trends; the values are identical in both. The climatological location of the tropopause is indicated with a thick black line for the mean climate, and with a thick red line for the expected tropopause location after 50 years assuming these trends persist. Statistical robustness of the trend is indicated by red and blue as discussed in section 2.2 .

the simple modeling experiment presented by Holloway and Neelin [2007]. Overall, the trend in the tropical circulation resembles the expected response to the trend in tropical moist heating.

[28] The seasonal evolution of the GEOSCCM model responses is summarized in Figure 9. The warming SSTs in the Indian ocean and warm pool region drive enhanced upper tropospheric heating (Figures 9a and 9b). The temperature response at $100 \mathrm{hPa}$ resembles qualitatively the response in JFM in the CCMVal-2 models and in the satellite data (Figure 9c versus Figures 3a, 3b, and 2). Note that there is less "noise" in the GEOSCCM trend than in the trend from satellite data as the GEOSCCM trends reflect the average of several ensemble members. In addition, the observational trends are weaker likely because the MSU weighting functions average over a range of altitudes. Future work is needed to understand the temperature trends in boreal spring and summer in these integrations and in the satellite data and CCMVal-2 models. In summary, these GEOSCCMtargeted integrations demonstrate that SSTs have modulated temperatures into the LS.

\section{Implications for Water Vapor, Ozone, and Radiation}

[29] The temperature and circulation trends impact trace gas concentrations in the UTLS. We first consider the impacts on water vapor, and then consider the impacts on ozone. Note that GEOSCCM can faithfully reproduce the impact of ENSO on water vapor [Garfinkel et al., 2013] and ozone [Oman et al., 2013], which enhances the confidence of its representation of the long-term trend.

\subsection{Water Vapor}

[30] As discussed in section 1, the climatological distribution of water vapor is heavily influenced by temperature near the cold point. It is therefore to be expected that the temperature trends shown in section 3 should impact the distribution of water vapor. We first focus on the trends in the lowermost stratosphere, and then focus on trends higher in the stratosphere.

[31] At $100 \mathrm{hPa}$, water vapor increases between $160^{\circ} \mathrm{E}$ and $140^{\circ} \mathrm{W}$ but decreases elsewhere (Figures $8 \mathrm{c}$ and $8 \mathrm{~g}$ ). Fueglistaler et al. [2004, Figure 3] show that most parcel trajectories entering the stratosphere in January and February (JF) dehydrate in the Western Pacific (see also Oman et al. [2008, Figures 1 and 4] and Garfinkel et al. [2013, Figure 2]). However, the climatological dehydration region extends beyond the dateline and into the Central Pacific (cf. Figure 10a); and in this region, lower stratospheric temperatures are increasing. This local temperature increase (Figure 4c) drives an increase in the saturation vapor pressure (Figures 10a and 10c), which therefore allows more water vapor to be present. It is therefore to be expected that water vapor concentrations increase locally near 180 (Figures $8 \mathrm{c}$ and $8 \mathrm{~g}$ ), as some of the final dehydration occurs in this region (Figures 10a and 10d). This is shown explicitly in Figure 6c, which compares the zonal structure of the temperature and water vapor trends at $85 \mathrm{hPa}$ at each longitude grid point: the correlation coefficient is 0.84 . Quantitatively, 
Trend in 6 member ensemble, 1980-2004, 20S-20N
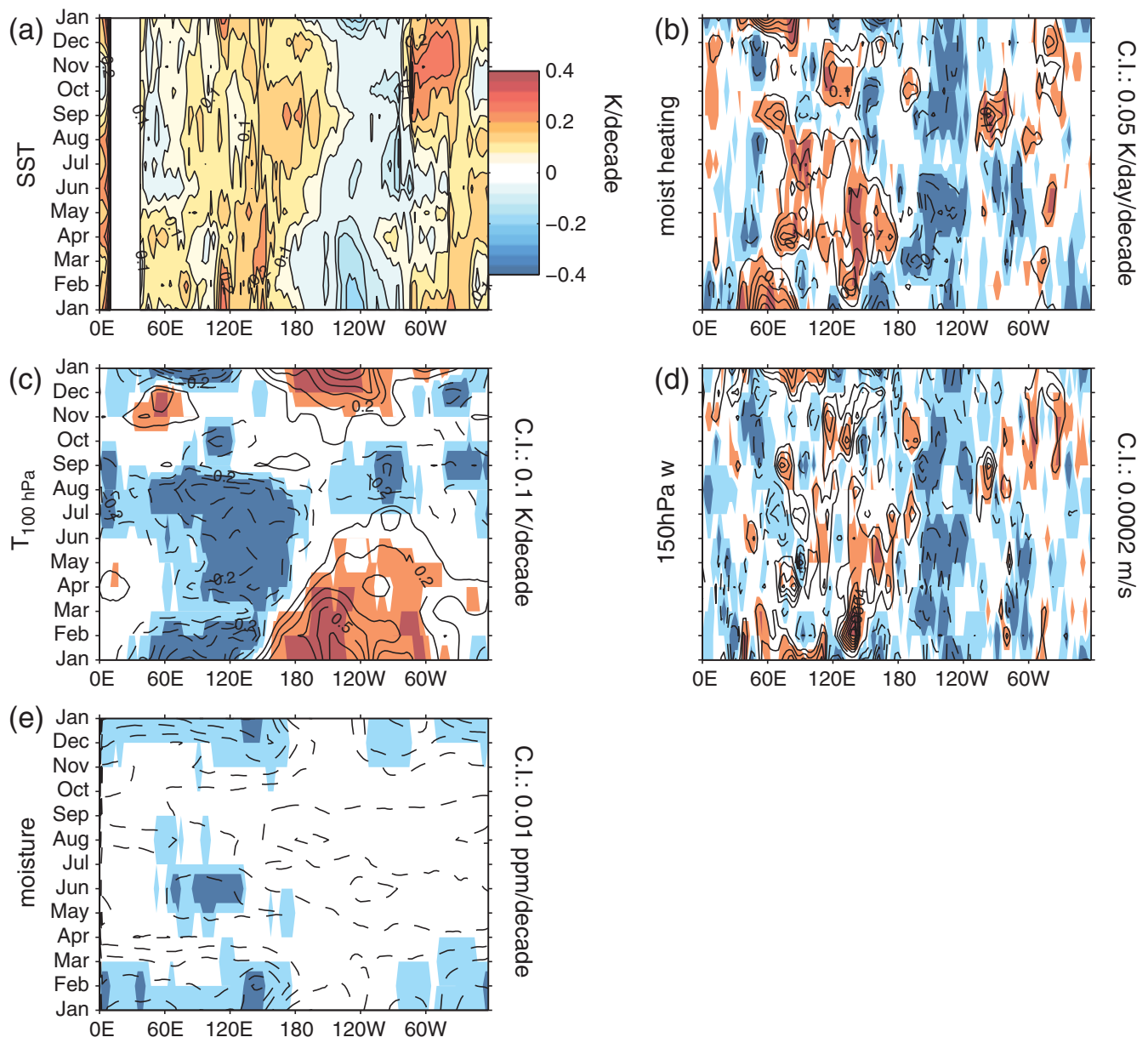

Figure 9. Summary of the trends in the Tropics in the SST-only GEOSCCM ensemble. (a) sea surface temperatures, (b) moist heating from 500 to $150 \mathrm{hPa}$, (c) temperature at $100 \mathrm{hPa}$, (d) vertical velocity at $150 \mathrm{hPa}$, and (e) water vapor pressure weighted from 85 to $50 \mathrm{hPa}$. The contour intervals are (Figure 9a) $0.05 \mathrm{~K} /$ decade, (Figure 9b) $0.05 \mathrm{~K} /$ day/decade, (Figure 9c) $0.1 \mathrm{~K} /$ decade, (Figure 9d) $2 \mathrm{e}-3 \mathrm{~m} / \mathrm{s} / \mathrm{decade}$, and (Figure 9e) $0.01 \mathrm{ppmv} /$ decade. Statistical robustness of the trend is indicated by red and blue. The zero contour is omitted.

the perturbation at $100 \mathrm{hPa}$ exceeds $7 \%$ per decade of the climatological mean state of water vapor.

[32] We note that the trend in water vapor is not driven by circulation changes (i.e., vertical advection). The circulation trend would oppose the effect of the temperature trend, as the circulation trend would tend to reduce (rather than increase) water vapor between $180^{\circ} \mathrm{W}$ and $120^{\circ} \mathrm{W}$ in the lowermost stratosphere (compare Figures $8 \mathrm{~b}$ and 8c). Quantitatively, the correlation coefficient between the zonal structure of the water vapor at $85 \mathrm{hPa}$ and vertical velocity trends at $100 \mathrm{hPa}$ at each longitude grid point is -0.26 ; vertical transport acts as a negative feedback on the zonal structure of water vapor. Rather, the effect of the temperature trend is dominant.

[33] The temperature trends near the tropopause also impact water vapor higher in the stratosphere. Stratospheric water vapor is dependent not on zonal-mean temperatures in the tropical tropopause region, but rather on the coldest temperature a given air parcel has encountered in its history [Mote et al., 1996]. In JFM, stratospheric water vapor is strongly associated with temperatures at the cold point over the warm pool [Fueglistaler et al., 2004]. Thus, water vapor concentrations in the stratosphere can decrease even if there is little zonally averaged response [e.g., Oman et al., 2008] and this is, in fact, what happens in our GEOSCCM-targeted ensemble. Because lower stratospheric temperatures over the warm pool region are decreasing (Figures $4 \mathrm{c}$ and $5 \mathrm{c}$ ), water vapor decreases in the model above $85 \mathrm{hPa}$. The reduction in water vapor above $85 \mathrm{hPa}$ is present in all calendar months (Figure 9e).

[34] Unfortunately, it is impossible to verify the model's simulation of the equatorial water vapor trend. The observational record is inconsistent over this period: Schoeberl et al. [2012] find that satellite and station based water vapor trends are inconsistent over the 1993-2010 period, and reanalysis products differ on the sign of the trends as well. However, the Boulder, Colorado balloon hygrometer water vapor record extends back to 1980 [Hurst et al., 2011], and we therefore discuss in the Appendix water vapor concentrations near Boulder from the model.

[35] In summary, water vapor trends at the tropopause can be explained by trends in saturation water vapor. In the lowermost stratosphere (i.e., above $70 \mathrm{hPa}$ ), water vapor 


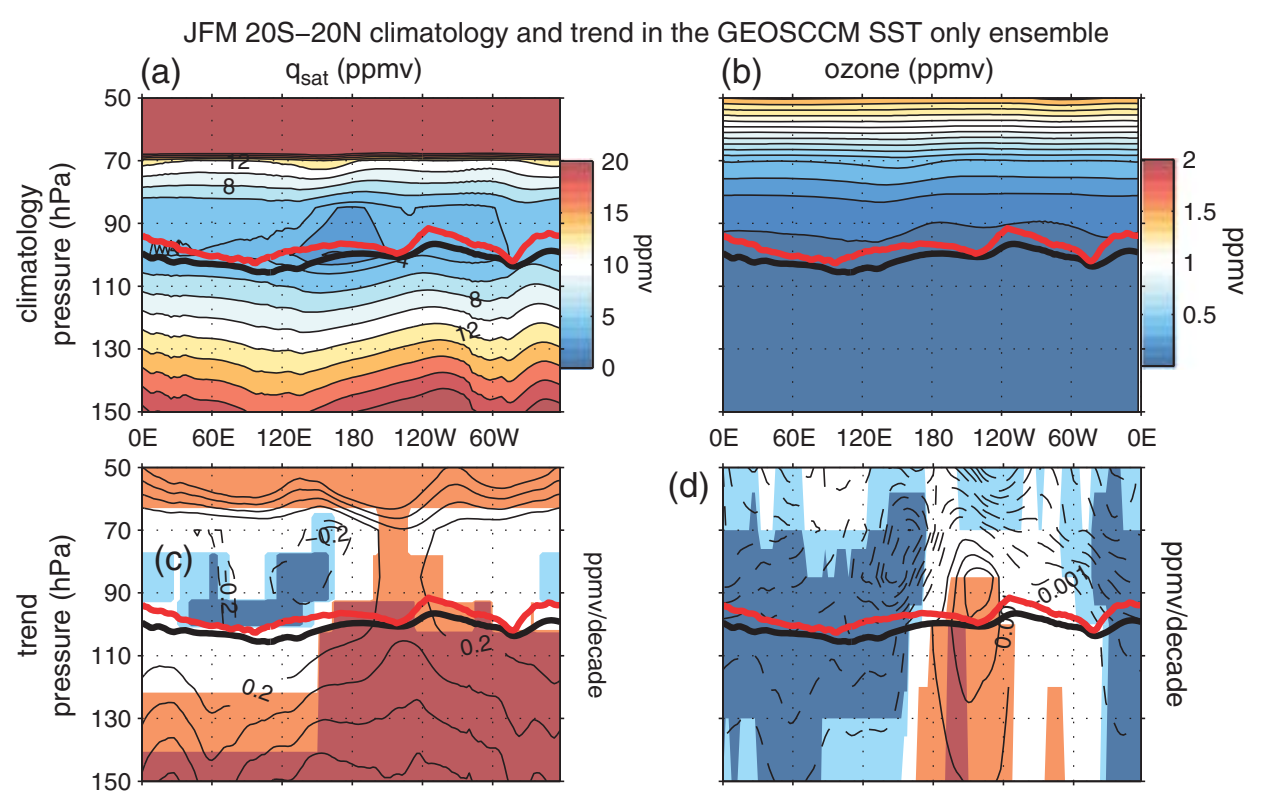

Figure 10. The climatology and trend in JFM in the ensemble mean of the GEOSCCM SST-only ensemble for ( $a$ and $c$ ) saturation vapor pressure and (b and d) ozone. The contour interval is (Figure 10a) 2 ppmv except that an extra contour is shown at 3 ppmv, (Figure 10c) 0.2 ppmv/decade, (Figure 10b) $0.1 \mathrm{ppmv}$, and (Figure 10d) 1e-3 ppmv/decade. The zero contour is omitted. The climatological location of the tropopause is indicated with a thick black line for the mean climate and with a thick red line for the expected tropopause location after 50 years assuming these trends persist. Statistical robustness of the trend is indicated by red and blue.

concentrations increase at longitudes that warm and decrease where there is cooling. At higher levels, water concentrations are determined by changes in the cold-point temperature at the tropopause: since the tropopause cold point is cooling, water vapor decreases uniformly above $70 \mathrm{hpa}$.

\subsection{Ozone}

[36] Although the changes in circulation are not the cause of the water vapor trends, these changes in circulation induced by the SST trends strongly modulate lower stratospheric ozone. Climatologically, there is a steep vertical gradient in ozone concentrations in the UTLS (Figure 10b), such that ozone concentrations differ by more than an order of magnitude between 150 and $70 \mathrm{hPa}$. Therefore, it is to be expected that any change in the circulation might be able to change, through vertical advection, the distribution of ozone and other trace gases with a sharp gradient in concentration between the stratosphere and troposphere.

[37] Our focus here is on the relative increase in ozone in the Eastern Pacific and a decrease in the Warm Pool region (Figure 10d) between 150 and $70 \mathrm{hPa}$. (The zonalmean decrease in stratospheric ozone above 70 hpa due to increases in tropical upwelling is consistent with e.g., Oman et al. [2009] and Garny et al. [2011]; a thorough discussion of the zonally averaged trend is beyond the scope of this work.) In order to understand this zonal structure, we examine the vertical velocity trend. As discussed in section 3, upwelling increases in the warm pool region (Figures $8 \mathrm{~b}$ and $8 \mathrm{f}$ ), and the increase in upwelling extends above the region where diabatic heating is near zero (as in Holloway and Neelin [2007]). This vertical motion can advect ozone. Specifically, upwelling in the warm pool region advects ozone-poor air into the LS (or possibly faster advection through the UTLS production region), while subsidence in the Eastern Pacific between $180^{\circ} \mathrm{W}$ and $120^{\circ} \mathrm{W}$ advects ozone rich air to below the tropopause. The net effect is that ozone trends closely resemble the vertical velocity trends (compare Figures $8 \mathrm{~b}$ and $8 \mathrm{f}$ to $10 \mathrm{~d}$ ). This is shown explicitly in Figure 6d, which compares the zonal structure of the vertical velocity trends at $100 \mathrm{hPa}$ to the ozone trends at 85 hpa at each longitude grid point: the correlation coefficient is -0.58 (the correlation coefficient at $150 \mathrm{hPa}$ is -0.41). While this correlation is lower than the others in Figure 6, it is still robust among the ensemble members. We expect that other trace gases with a sharp gradient in their concentration between the stratosphere and troposphere will be affected in a manner very similar to ozone.

\subsection{Feedbacks From Radiation}

[38] Thus far, we have been focusing on dynamical changes induced by warming SST and increased convective heating. We now consider how the changes in water vapor discussed above feed back on the temperature changes. Tropospheric moist heating is increased in the Indian Ocean region and warm pool region as discussed above (Figure 8e); however, the changes in the LS are minor (Figure 8a). In contrast, radiative heating changes (Figures $8 \mathrm{~d}$ and $8 \mathrm{~h}$ ) are minor in the troposphere but are important in the LS. Quantitatively, the perturbation exceeds $12.5 \%$ of the climatological radiative heating at $70 \mathrm{hPa}$ over the duration of the integrations (i.e., 5\% per decade). In the regions in the LS where moisture is increasing (Figure 8c), radiative heating is decreasing because water vapor is a very efficient $\mathrm{GHG}$ at these altitudes. In contrast, regions that are dehydrating 

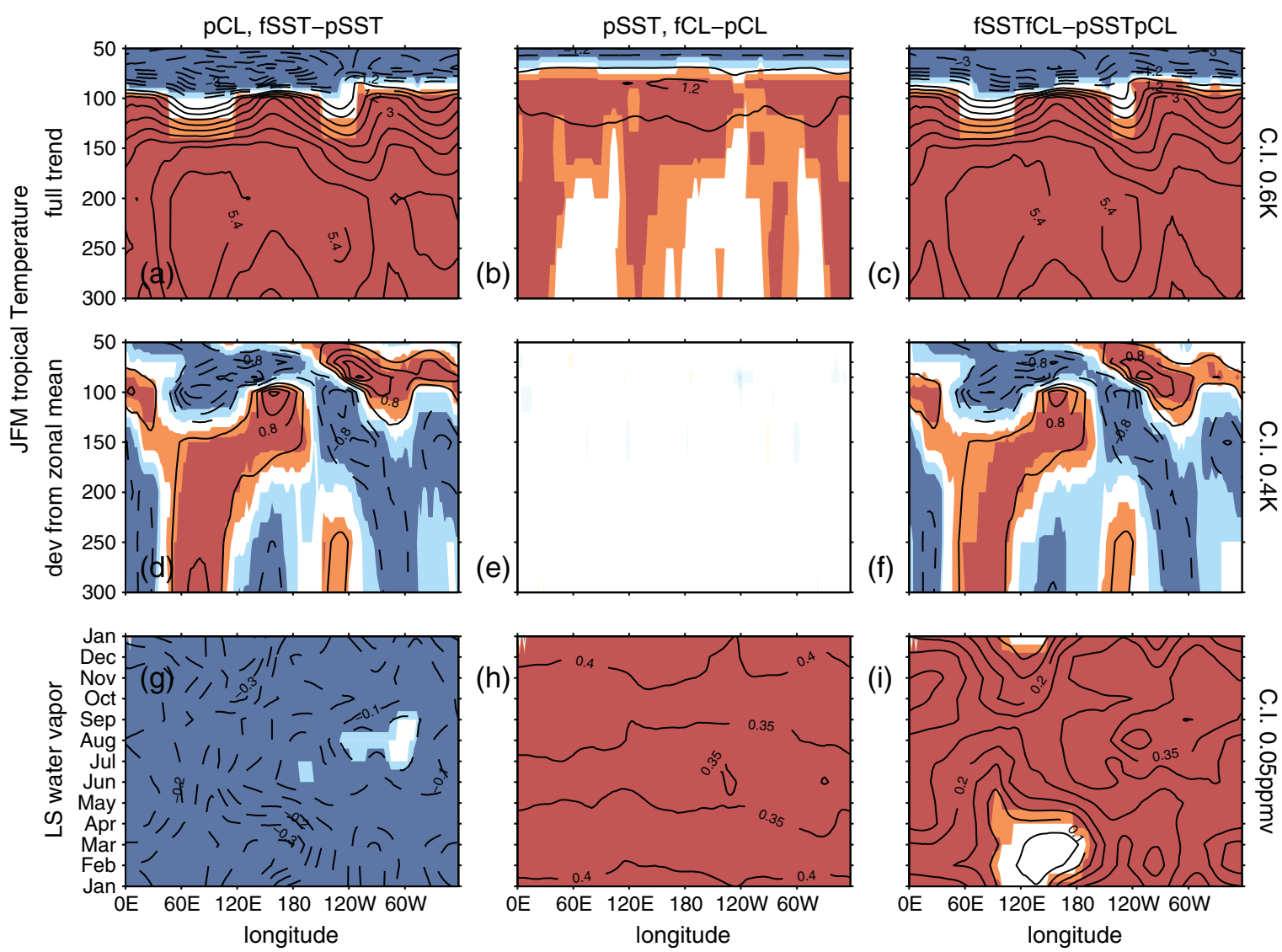

(e)
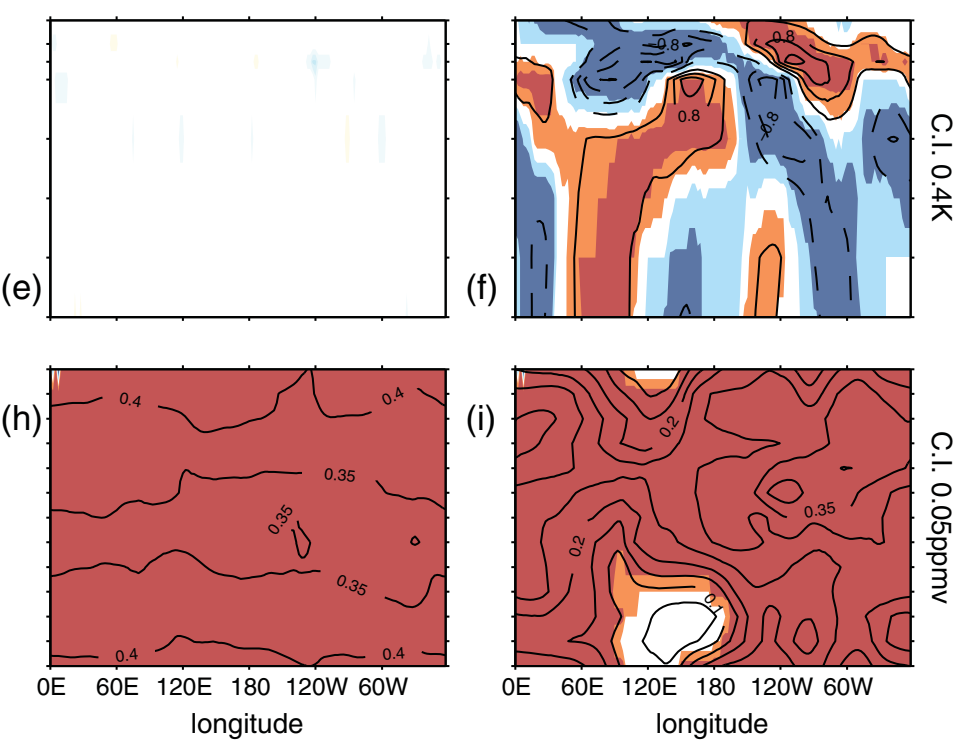

Figure 11. Temperature anomalies in the upper troposphere and lower stratosphere, and lower stratospheric moisture pressure weighted from 85 to $50 \mathrm{hPa}$, in the Tropics in the GEOSCCM-targeted integrations of the future climate. ( $\mathrm{a}, \mathrm{d}, \mathrm{g}$ ) Isolates the impact of changing SSTs only (pCL, fSST-pSST). $(b, e, h)$ Isolates the impact of changing gas concentrations only (pSST, fCL-pCL). (c, f, i) Both gas concentrations and SSTs are changed (fSSTfCL-pSSTpCL). (Figures 11a-11c) Temperature change as a function of longitude and pressure in JFM (contour interval: $0.6 \mathrm{~K}$ ). (Figures 11d-11f) Zonally asymmetric component of top row in JFM (contour interval: $0.4 \mathrm{~K}$ ). (Figures 11g-11i) Lower stratospheric moisture pressure weighted from 85 to $50 \mathrm{hPa}$ (contour interval: $0.05 \mathrm{ppmv}$ ). Statistical robustness of the anomalies is indicated by red and blue. The zero contour is omitted. The anomalies in Figure 11e are not statistically significant and do not exceed the threshold contour interval.

are warmed by radiative heating because the local emissivity is decreasing. Recall that the temperatures were decreasing where water vapor was decreasing. Thus, the trend in radiative heating acts as a negative feedback on the temperature changes. In other words, the lower stratospheric temperature response to rising SSTs is opposed, but only partially, by changes in water vapor.

\section{Future Changes in SSTs}

[39] Thus far, we have shown that past SST changes have impacted temperatures and the circulation near the tropical cold point. In this section, we briefly consider the future. Specifically, we address the question: will future changes in SSTs lead to similar changes in the UTLS region, and thus will the changes forced by the observed SST trend continue in the future? To answer this question, we examine the temperature and water vapor response in the group of experiments labeled " $\mathrm{D}$ " in Table 1 that were introduced in section 2. Figures $11 \mathrm{a}, 11 \mathrm{~d}$, and $11 \mathrm{~g}$ show the change in temperature and water vapor associated with increased SSTs only. The historical and future responses in the LS region are generally similar, whereby the LS region cools most strongly in JFM over the Indian Ocean from $\sim 60^{\circ} \mathrm{E}$ to $\sim 120^{\circ} \mathrm{E}$ and warms relative to the zonal mean in the Pacific $\left(\sim 150^{\circ} \mathrm{W}\right)$. At the $85 \mathrm{hPa}$ level, the cold temperature anomaly over the Indian Ocean extends into the warm pool region while the warm anomaly over the Pacific weakens, as in Figures $4 \mathrm{c}$ and $4 \mathrm{~d}$. Stratospheric water vapor is reduced (Figure $11 \mathrm{~g}$ ). If SSTs evolve as simulated by CCSM3, we would expect that the observed zonal structure of the atmospheric temperature trends will continue in the future.

[40] The changes in lower stratospheric water vapor due to SST changes are of comparable magnitude, but of opposite sign, to those due to increased $\mathrm{CO}_{2}$ and methane and from ozone recovery. In order to demonstrate this effect, we show in Figures $11 \mathrm{~b}, 11 \mathrm{e}$, and $11 \mathrm{~h}$ the change in temperature and water vapor for the integration with future GHG and ODS concentrations but present-day SSTs. Tropical tropopause temperatures warm by $\sim 1 \mathrm{~K}$ [e.g., Oman et al., 2008] which results in a $\sim 0.45$ ppmv increase in lower stratospheric water vapor. However, these changes are 
largely independent of longitude time of year. The key point is that the SST only effect and the gas concentration effect are of similar magnitude.

[41] Finally, we consider an experiment in which all of the future changes occur: SSTs warm, GHG increases, and ODS are reduced. The temperature anomalies in the LS are shown in Figures 11c and 11f. Quantitatively, the changes resemble the sum of the independent responses to SST warming and changing gas concentrations; in other words, the responses add linearly. The zonal structure of the change is dominated by the SSTs. Hurwitz et al. (submitted manuscript, 2013) will show that future changes in ENSO extratropical teleconnections are dominantly driven by changes in modeled SSTs.) It is therefore important that both the direct contribution from well-mixed GHGs and the future evolution of the SSTs in different ocean basins be considered for projections of future stratospheric water vapor and cold-point temperatures. While chemistry-climate models coupled to an ocean are necessary before firm conclusions can be reached as to the relative importance of SSTs and gas concentrations, we strongly recommend that close attention be paid to the pattern of SST warming in projections of future climate.

\section{Discussion}

[42] We now discuss our results in the context of previous work that relates to SST-driven temperature trends near the tropical tropopause. Shu et al. [2011, cf. Figure 11] find that the cold-point temperature increases if SSTs are increased everywhere, which is seemingly contrary to our finding in which the cold-point temperature have decreased and will continue to do so in the future. However, Shu et al. [2011] applied a uniform increase in SSTs everywhere, while we impose a specific pattern of SST increase as derived from a coupled ocean-atmosphere model.

[43] One might hypothesize that the zonal structure of the temperature trend is due to aliasing of an ENSO signal, as ENSO clearly impacts temperatures in the tropical lower stratosphere [Kiladis et al., 2001; Calvo Fernández et al., 2004; Scherllin-Pirscher et al., 2012; Garfinkel et al., 2013]. Scaife et al. [2003] further argue that El Niño frequency has increased (a more recent discussion of changes in Pacific Ocean SSTs and ENSO frequency can be found in L'Heureux et al. [2012], Luo et al. [2012], and Sohn et al. [2012]), and thus SST changes may have led to warmer coldpoint temperatures. The present study suggests that trends in ENSO frequency have not caused the trends in the cold-point temperatures. The SST trend resembles neither El Niño nor La Niña. While the SST anomalies in the Pacific and Warm pool region resemble (if anything) La Niña, the SST anomalies in the Indian Ocean resemble (if anything) El Niño. For example, the correlation coefficient of the Nino3.4 index (i.e., SSTa from $5^{\circ} \mathrm{S}$ to $5^{\circ} \mathrm{N}, 120^{\circ} \mathrm{W}-170^{\circ} \mathrm{W}$ ) with equatorial Indian Ocean SSTs from $50^{\circ} \mathrm{E}$ to $100^{\circ} \mathrm{E}$ is 0.74 ; see also Garfinkel et al. [2013, Figure 2]. The trend can therefore not be understood as a change in the relative frequencies of El Niño and La Niña, unlike in Scaife et al. [2003]. In addition, we have used linear regression to statistically remove the linear influence of ENSO from the $100 \mathrm{hPa}$ temperatures before computing the trends, and the trends are quantitatively similar (not shown). Finally, the trends are robust to alterations of the start and end date, and thus to excluding individual ENSO years near the endpoints (e.g., Figure 1). Overall, SST changes have led to reduced stratospheric water vapor as suggested by Rosenlof and Reid [2008] and Zhou et al. [2001].

[44] We note that the tropospheric circulation trends in the targeted GEOSCCM integrations appear to reflect a strengthening of the tropospheric Pacific Walker Circulation, consistent with L'Heureux et al. [2013]. Finally, the correlation coefficient of the Pacific Decadal Oscillation index and stratospheric water vapor in these integrations is not robust among the ensemble members, which implies that the temperature trend structure is not (directly) caused by the phase of the Pacific Decadal Oscillation.

\section{Conclusions}

[45] Satellite observations and chemistry-climate model simulations are used to explore the impact of sea surface temperature trends on upper tropospheric and lower stratospheric temperatures. In the satellite era, the tropical upper troposphere has warmed most strongly near the Indo-Pacific warm pool, while the temperature trends in the western and central Pacific are much weaker. In the lower stratosphere, these trends are reversed: the historical cooling trend is strongest over the Indo-Pacific warm pool and is weaker in the western and central Pacific. Nearly all of the comprehensive chemistry-climate models integrations submitted to the CCMVal-2 project demonstrate this effect, suggesting that it is a robust feature of the atmospheric circulation over the past 30 years.

[46] The zonal variations are stronger than the zonal-mean response in boreal winter. Furthermore, the zonal variations appear to be more robust than the zonal-mean response. While the zonal-mean increase in tropical upwelling is certainly important for the overall structure of the stratosphere, it is swallowed by the zonal structure below $70 \mathrm{hPa}$. In other words, the (zonal-mean) Brewer-Dobson circulation blurs together robust regional signals and is thus a crude and incomplete diagnostic of changes in the tropical lower stratosphere in a changing climate.

[47] Targeted experiments with a chemistry-climate model (GEOSCCM) are then used to isolate the impact of SST variability on this zonal structure in upper tropospheric and lower stratospheric tropical temperature trends. In these experiments, GEOSCCM is forced with only one source of externally-imposed variability: sea surface temperatures follow those observed. Warming sea surface temperatures in the Indian Ocean and in the warm pool region lead to enhanced upper tropospheric moist heating, and in turn to a Gill-like response in the upper troposphere and lower stratosphere. The upwelling and subsidence associated with the Gill-like response extend above the tropopause, such that the anomalous circulation directly affects lower stratospheric ozone and water vapor. The Gill-like response also leads to cooling of the cold-point tropopause and thus to less water vapor entering the stratosphere. These changes in lower stratospheric composition feed back on the radiative budget in the lower stratosphere; the radiative feedbacks are smaller than the direct changes forced by the SSTs.

[48] Finally, these changes could persist into the future, depending on the evolution of SSTs in the Indian and Pacific 
basins. The changes in water vapor and temperature due to projected future sea surface temperatures are of similar strength to, though slightly weaker than, that due directly to projected future $\mathrm{CO}_{2}$, ozone, and methane. It is therefore of paramount importance that attention be paid to the precise pattern of SST warming in chemistry-ocean-atmosphere simulations performed for future assessments.

\section{Appendix A}

[49] The longest record of observed water vapor is from Boulder, Colorado, and we therefore wish to compare the modeled water vapor to that observed. Note that methane concentrations are held constant in these integrations. Figure A1 shows the annual averaged water vapor concentrations at the grid point closest to Boulder. First, the model appears to have too little water vapor variability in comparison to the Boulder hygrometer data (even though it captures the mean state very well; compare to Hurst et al. [2011, Figure 2]), its variability compares well to that in the Halogen Occultation Experiment (HALOE) record [Fueglistaler et al., 2013, Figure 11]. Over the full length of these integrations, there is a decline in water vapor over Boulder (as in equatorial water vapor) in all ensemble members at $50 \mathrm{hPa}$. However, at $100 \mathrm{hPa}$, some ensemble members show an increase (not shown), but the largest growth rate was $0.04 \mathrm{ppmv} / \mathrm{dec}$ ade which is much smaller than in the Boulder hygrometer record. Even at $50 \mathrm{hPa}$, water vapor increases over shorter periods. Specifically, the lack of a trend in water vapor concentrations from 1992 to 2000 in the model matches that found in the HALOE data [Fueglistaler et al., 2013, Figure 11]. Finally, five of the six ensemble members indicate a steep decline in water vapor in the early 2000 s, but this decline is not unusual when compared to other periods of declining water vapor in these integrations. In addition, the timing of the abrupt drop and the subsequent recovery does not appear to match that observed and is also variable among the ensemble members. Five of the six ensemble members extend until December 2009, and over the additional years, water vapor concentrations con-

$\mathrm{H}_{2} \mathrm{O}$ at $40 \mathrm{~N}, 105 \mathrm{~W}, 50 \mathrm{hPa}$ (Boulder, CO)

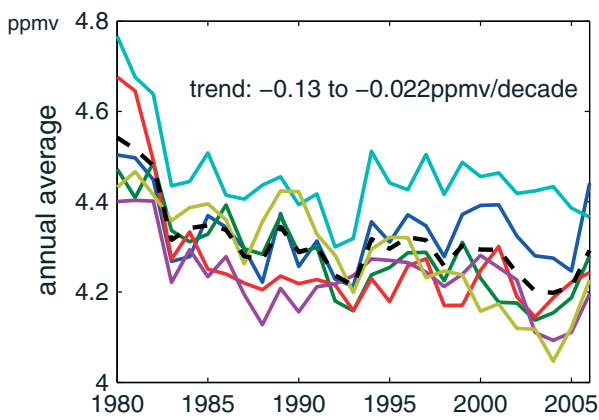

Figure A1. The annual averaged water vapor at the grid point closest to Boulder, Colorado $\left(40^{\circ} \mathrm{N}, 105^{\circ} \mathrm{W}\right)$ in the GEOSCCM SST-only ensemble at $50 \mathrm{hPa}$. The ensemble mean is indicated by a dashed black line, and each of the six ensemble members is indicated by a colored line. At this location, the trends range among the ensemble members from $-0.12 \mathrm{ppmv} /$ decade to $-0.02 \mathrm{ppmv} /$ decade as indicated in the Figure. tinue to rise; the increase in water vapor from the minimum in 2004 to the maximum in 2009 is 0.2 ppmv. There are at least three possible interpretations of these results: (a) GEOSCCM is insufficiently realistic to capture the observed water vapor variability, (b) external forcings besides SSTs have driven stratospheric water vapor variability over Boulder, and/or (c) internal variability of water vapor is sufficiently strong that model integrations should not be expected to replicate all (or even most) of the observed variability. A thorough investigation is beyond the scope of this work.

[50] Acknowledgments. This work was supported by NSF grants AGS-1036858 and ATM-0905863. We acknowledge the very helpful feedback from George Kiladis, Karen Rosenlof, and two anonymous reviewers.

\section{References}

Calvo Fernández, N., R. R. García, R. García Herrera, D. Gallego Puyol, L. Gimeno Presa, E. Hernández Martín, and P. Ribera Rodríguez (2004), Analysis of the ENSO signal in tropospheric and stratospheric temperatures observed by MSU, 1979 2000, J. Clim., 17, 3934-3946, doi:10.1175/1520-0442(2004)017<3934:AOTESI >2.0.CO;2.

Deckert, R., and M. Dameris (2008), Higher tropical SSTs strengthen the tropical upwelling via deep convection, Geophys. Res. Lett., 35, L10813, doi:10.1029/2008GL033719.

Eyring, V., et al. (2008), Overview of the new CCMVAL reference and sensitivity simulations in support of upcoming ozone and climate assessments and the planned SPARC CCMVAL report, SPARC Newslett., 30 , 20-26.

Fu, Q., C. M. Johanson, J. M. Wallace, and T. Reichler (2006), Enhanced mid-latitude tropospheric warming in satellite measurements, Science, 312(5777), 1179, doi:10.1126/science.1125566.

$\mathrm{Fu}$, Q., S. Solomon, and P. Lin (2010), On the seasonal dependence of tropical lower-stratospheric temperature trends, Atmos. Chem. Phys., 10, 2643-2653.

Fueglistaler, S., H. Wernli, and T. Peter (2004), Tropical troposphere-tostratosphere transport inferred from trajectory calculations, J. Geophys. Res., 109, D03108, doi:10.1029/2003JD004069.

Fueglistaler, S., A. E. Dessler, T. J. Dunkerton, I. Folkins, Q. Fu, and P. W. Mote (2009), Tropical tropopause layer, Rev. Geophys., 47, RG1004, doi:10.1029/2008RG000267.

Fueglistaler, S., et al. (2013), The relation between atmospheric humidity and temperature trends for stratospheric water, J. Geophys. Res. Atmos., 118, 1052-1074, doi:10.1002/jgrd.50157.

Garcia, R. R., D. Marsh, D. Kinnison, B. Boville, and F. Sassi (2007), Simulations of secular trends in the middle atmosphere, 1950-2003, J. Geophys. Res., 112, D09301, doi:10.1029/2006JD007485.

Garfinkel, C. I., M. Hurwitz, L. Oman, and D. W. Waugh (2013), Contrasting effects of Central Pacific and Eastern Pacific El Niño on stratospheric water vapor, Geophys. Res. Lett., 40, 4115-4120, doi:10.1002/grl.50677.

Garny, H., M. Dameris, W. Randel, G. E. Bodeker, and R. Deckert (2011), Dynamically forced increase of tropical upwelling in the lower stratosphere, J. Atmos. Sci., 68, 1214-1233.

Gettelman, A., et al. (2010), Multimodel assessment of the upper troposphere and lower stratosphere: Tropics and global trends, J. Geophys. Res., 115, D00M08, doi:10.1029/2009JD013638.

Gill, A. E. (1980), Some simple solutions for heat-induced tropical circulation, Q. J. R. Meteorolog. Soc., 106, 447-462, doi:10.1002/ qj. 49710644905 .

Grise, K. M., and D. W. J. Thompson (2013), On the signatures of equatorial and extratropical wave forcing in tropical tropopause layer temperatures, J. Atmos. Sci., 70, 1084-1102, doi:10.1175/JAS-D-12-0163.1.

Highwood, E. J., and B. J. Hoskins (1998), The tropical tropopause, Q. J. R. Meteorolog. Soc., 124, 1579-1604, doi:10.1002/qj. 49712454911.

Hoerling, M. P., J. W. Hurrell, T. Xu, G. T. Bates, and A. S. Phillips (2004), Twentieth century North Atlantic climate change. Part II: Understanding the effect of Indian Ocean warming, Clim. Dyn., 23, 391-405, doi:10.1007/s00382-004-0433-x.

Holloway, C. E., and J. D. Neelin (2007), The convective cold top and quasi equilibrium*, J. Atmos. Sci., 64, 1467-1487, doi:10.1175/JAS3907.1.

Hurst, D. F., S. J. Oltmans, H. Vömel, K. H. Rosenlof, S. M. Davis, E. A Ray, E. G. Hall, and A. F. Jordan (2011), Stratospheric water vapor trends over Boulder, Colorado: Analysis of the 30 year Boulder record, J. Geophys. Res., 116, D02306, doi:10.1029/2010JD015065. 
Hurwitz, M., I.-S. Song, L. Oman, P. Newman, A. Molod, S. Frith, and J. Nielsen (2011), Response of the Antarctic stratosphere to warm pool El Niño events in the GEOS CCM, Atmos. Chem. Phys., 11, 9659-9669, doi:10.5194/acp-11-9659-2011.

Hurwitz, M. M., P. A. Newman, F. Li, L. D. Oman, O. Morgenstern, P. Braesicke, and J. A. Pyle (2010), Assessment of the breakup of the Antarctic polar vortex in two new chemistry-climate models, J. Geophys. Res., 115, D07105, doi:10.1029/2009JD012788.

Kiladis, G. N., K. H. Straub, G. C. Reid, and K. S. Gage (2001), Aspects of interannual and intraseasonal variability of the tropopause and lower stratosphere, Q. J. R. Meteorolog. Soc., 127, 1961-1983, doi:10.1002/qj.49712757606.

Knutson, T. R., T. L. Delworth, K. W. Dixon, and R. J. Stouffer (1999), Model assessment of regional surface temperature trends (1949-1997), J. Geophys. Res., 104, 30,981-30,996, doi:10.1029/1999JD900965.

Knutson, T. R., T. L. Delworth, K. W. Dixon, I. M. Held, J. Lu, V. Ramaswamy, M. D. Schwarzkopf, G. Stenchikov, and R. J. Stouffer (2006), Assessment of twentieth-century regional surface temperature trends using the GFDL CM2 Coupled Models, J. Clim., 19, 1624, doi:10.1175/JCLI3709.1.

Kodama, C., T. Iwasaki, K. Shibata, and S. Yukimoto (2007), Changes in the stratospheric mean meridional circulation due to increased co2: Radiation-and sea surface temperature-induced effects, J. Geophys. Res., 112, D16103, doi:10.1029/2006JD008219.

L'Heureux, M. L., D. C. Collins, and Z.-Z. Hu (2012), Linear trends in sea surface temperature of the tropical Pacific Ocean and implications for the El Niño-Southern Oscillation, Clim. Dyn., 40, 1223-1236, doi:10.1007/s00382-012-1331-2.

L'Heureux, M. L., S. Lee, and B. Lyon (2013), Recent multidecadal strengthening of the walker circulation across the tropical pacific, Nat. Clim. Change, 3(6), 571-576.

Luo, J.-J., W. Sasaki, and Y. Masumoto (2012), Indian Ocean warming modulates Pacific climate change, Proc. Natl. Acad. Sci., 109(46), $18,701-18,706$.

Mears, C. A., and F. J. Wentz (2009), Construction of the remote sensing systems V3.2 atmospheric temperature records from the MSU and AMSU microwave sounders, J. Atmos. Oceanic Technol., 26, 1040, doi:10.1175/2008JTECHA1176.1

Mears, C. A., M. C. Schabel, and F. J. Wentz (2003), A reanalysis of the MSU channel 2 tropospheric temperature record., J. Clim., 16, 36503664, doi:10.1175/1520-0442(2003)016<3650:AROTMC $>2.0$.CO;2.

Molod, A., et al. (2012), The GEOS-5 atmospheric general circulation model: Mean climate and development from MERRA to Fortuna, in Technical Report Series on Global Modeling and Data Assimilation, vol. 28, edited by M. J. Suarez, NASA, Washington, D. C.

Moorthi, S., and M. J. Suarez (1992), Relaxed Arakawa-Schubert. A parameterization of moist convection for general circulation models, Mon. Wea. Rev., 120, 978-1002, doi:10.1175/1520-0493(1992)120< 0978:RASAPO $>2.0 . \mathrm{CO} ; 2$.

Mote, P. W., et al. (1996), An atmospheric tape recorder: The imprint of tropical tropopause temperatures on stratospheric water vapor, $J$. Geophys. Res., 101, 3989-4006, doi:10.1029/95JD03422.

Nishimoto, E., and M. Shiotani (2012), Seasonal and interannual variability in the temperature structure around the tropical tropopause and its relationship with convective activities, J. Geophys. Res., 117, D02104, doi:10.1029/2011JD016936.

Olsen, M. A., M. R. Schoeberl, and J. E. Nielsen (2007), Response of stratospheric circulation and stratosphere-troposphere exchange to changing sea surface temperatures, J. Geophys. Res., 112, D16104, doi:10.1029/2006JD008012.

Oman, L., D. W. Waugh, S. Pawson, R. S. Stolarski, and J. E. Nielsen (2008), Understanding the changes of stratospheric water vapor in coupled chemistry-climate model simulations, J. Atmos. Sci., 65, 3278-3291, doi:10.1175/2008JAS2696.1.

Oman, L., D. W. Waugh, S. Pawson, R. S. Stolarski, and P. A. Newman (2009), On the influence of anthropogenic forcings on changes in the stratospheric mean age, J. Geophys. Res., 114, D03105, doi:10.1029/2008JD010378.

Oman, L. D., A. R. Douglass, J. R. Ziemke, J. Rodriguez, D. W. Waugh, and J. E. Nielsen (2013), The ozone response to ENSO in aura satellite measurements and a chemistry-climate simulation, J. Geophys. Res. Atmos., 118, 965-976, doi:10.1029/2012JD018546.

Pawson, S., R. S. Stolarski, A. R. Douglass, P. A. Newman, J. E. Nielsen, S. M. Frith, and M. L. Gupta (2008), Goddard Earth observing system chemistry-climate model simulations of stratospheric ozone-temperature coupling between 1950 and 2005, J. Geophys. Res., 113, D12103, doi:10.1029/2007JD009511

Po-Chedley, S., and Q. Fu (2012), Discrepancies in tropical upper tropospheric warming between atmospheric circulation models and satellites, Environ. Res. Lett., 7(4), 044018, doi:10.1088/1748-9326/7/4/044018.
Randel, W. J., and E. J. Jensen (2013), Physical processes in the tropical tropopause layer and their roles in a changing climate, Nat. Geosci., 6, 169-176, doi:10.1038/ngeo1733.

Randel, W. J., et al. (2009), An update of observed stratospheric temperature trends, J. Geophys. Res., 114, D02107, doi:10.1029/ 2008JD010421.

Rayner, N. A., D. E. Parker, E. B. Horton, C. K. Folland, L. V. Alexander, D. P. Rowell, E. C. Kent, and A. Kaplan (2003), Global analyses of sea surface temperature, sea ice, and night marine air temperature since the late nineteenth century, J. Geophys. Res., 108, 4407, doi:10.1029/ 2002JD002670.

Rienecker, M. M., et al. (2011), MERRA: NASA's Modern-Era Retrospective Analysis for Research and Applications, J. Clim., 24, 3624-3648, doi:10.1175/JCLI-D-11-00015.1.

Rienecker, M. M., et al. (2008), The GEOS-5 data assimilation system Documentation of versions 5.0.1, 5.1.0, and 5.2.0, Technical Report Series on Global Modeling and Data Assimilation, vol. 27, edited by M. J. Suarez, NASA, Washington D. C.

Rosenlof, K. H., and G. C. Reid (2008), Trends in the temperature and water vapor content of the tropical lower stratosphere: Sea surface connection, J. Geophys. Res., 113, D06107, doi:10.1029/2007JD009109.

Ryu, J.-H., and S. Lee (2010), Effect of tropical waves on the tropical tropopause transition layer upwelling, J. Atmos. Sci., 67, 3130-3148, doi:10.1175/2010JAS3434.1

Scaife, A. A., N. Butchart, D. R. Jackson, and R. Swinbank (2003), Can changes in ENSO activity help to explain increasing stratospheric water vapor?, Geophys. Res. Lett., 30(17), 1880, doi:10.1029/2003GL017591.

Scherllin-Pirscher, B., C. Deser, S.-P. Ho, C. Chou, W. Randel, and Y.-H. Kuo (2012), The vertical and spatial structure of enso in the upper troposphere and lower stratosphere from GPS radio occultation measurements, Geophys. Res. Lett., 39, L20801, doi:10.1029/ 2012 GL053071.

Schoeberl, M. R., A. E. Dessler, and T. Wang (2012), Simulation of stratospheric water vapor and trends using three reanalyses, Atmos. Chem. Phys., 12, 6475-6487, doi:10.5194/acp-12-6475-2012.

Seidel, D. J., N. P. Gillett, J. R. Lanzante, K. P. Shine, and P. W. Thorne (2011), Stratospheric temperature trends: Our evolving understanding, Wiley Interdiscip. Rev. Clim. Change, 2(4), 592-616, doi:10.1002/ wcc. 125.

Seidel, D. J., M. Free, and J. S. Wang (2012), Reexamining the warming in the tropical upper troposphere: Models versus radiosonde observations, Geophys. Res. Lett., 39, L22701, doi:10.1029/2012GL053850.

Shu, J., W. Tian, J. Austin, M. P. Chipperfield, F. Xie, and W. Wang (2011), Effects of sea surface temperature and greenhouse gas changes on the transport between the stratosphere and troposphere, J. Geophys. Res., 116, D02124, doi:10.1029/2010JD014520.

Sohn, B. J., S.-W. Yeh, J. Schmetz, and H.-J. Song (2012), Observational evidences of Walker circulation change over the last 30 years contrasting with GCM results, Clim. Dyn., 40, 1721-1732, doi:10.1007/s00382-0121484-z.

Solomon, S., D. Qin, M. Manning, Z. Chen, M. Marquis, K. Averyt, M. Tignor, and H. Miller (eds.) (2007), Contribution of Working Group I to the Fourth Assessment Report of the Intergovernmental Panel on Climate Change, Cambridge Univ. Press, Cambridge, United Kingdom and New York, NY, USA.

SPARC-CCMVal, (2010), SPARC report on the evaluation of chemistryclimate models, SPARC Report, 5, WCRP-132, WMO/TD-No. 1526.

Ting, M., and I. M. Held (1990), The stationary wave response to a tropical SST anomaly in an idealized GCM., J. Atmos. Sci., 47, 2546-2566, doi:10.1175/1520-0469(1990)047<2546:TSWRTA $>2.0$. $\mathrm{CO} ; 2$

Wang, J. S., D. J. Seidel, and M. Free (2012), How well do we know recent climate trends at the tropical tropopause?, J. Geophys. Res., 117, D09118, doi:10.1029/2012JD017444.

Wang, L., and D. W. Waugh (2012), Chemistry-climate model simulations of recent trends in lower stratospheric temperature and stratospheric residual circulation, J. Geophys. Res., 117, D09109, doi:10.1029/2011JD017130.

World Meteorological Organization (2011), Scientific Assessment of Ozone Depletion: 2010. 516 pp., Global Ozone Research and Monitoring Project Rep. No. 52.

Young, P. J., D. W. J. Thompson, K. H. Rosenlof, S. Solomon, and J.-F. Lamarque (2011), The seasonal cycle and interannual variability in stratospheric temperatures and links to the Brewer-Dobson circulation: An analysis of MSU and SSU data, J. Clim., 24, 6243-6258, doi:10.1175/JCLI-D-10-05028.1.

Zhou, X.-L., M. A. Geller, and M. Zhang (2001), Cooling trend of the tropical cold point tropopause temperatures and its implications, J. Geophys. Res., 106, 1511-1522, doi:10.1029/ 2000JD900472. 